\title{
The economics of minority language use: theory and empirical evidence for a language game model
}

\author{
Stefan Sperlich* José-Ramón Uriarte ${ }^{\dagger}$
}

September 2, 2019

\begin{abstract}
Language and cultural diversity is a fundamental aspect of the present world. We study three modern multilingual societies -the Basque Country, Ireland and Wales- which are endowed with two, linguistically distant, official languages: $A$, spoken by all individuals, and $B$, spoken by a bilingual minority. In the three cases it is observed a decay in the use of minoritarian $B$, a sign of diversity loss. However, for the Council of Europe the key factor to avoid the shift of $B$ is its use in all domains. Thus, we investigate the language choices of the bilinguals by means of an evolutionary game theoretic model. We show that the language population dynamics has reached an evolutionary stable equilibrium where a fraction of bilinguals have shifted to speak $A$. Thus, this equilibrium captures the decline in the use of $B$. To test the theory we build empirical models that predict the use of $B$ for each proportion of bilinguals. We show that model-based predictions fit very well the observed use of Basque, Irish, and Welsh 1
\end{abstract}

Keywords: economics of language, language use game, evolutionary stability, threatened languages.

JEL codes: Z1, H89, C72, C57

${ }^{*}$ Geneva School of Economics and Management, Université de Genève, Bd du Pont d'Arve 40, CH-1211 Genève, Suisse. E-mail address: stefan.sperlich@unige.de.

${ }^{\dagger}$ Corresponding author: University of the Basque Country, Departamento de Fundamentos del Análisis Económico I, Avenida Lehendakari Aguirre 83, E-48015 Bilbao, Basque Country-Spain. E-mail address: jr.uriarte@ehu.es

${ }^{1}$ This joint work started while José-Ramón Uriarte was visiting the Humbolt-Universität zu Berlin and the University of Geneva. He would like to thank the generous hospitality of both universities. Financial support provided by the Basque Government, by the Ministerio de Economía y Competitividad (ECO2012-31626, ECO2016-76203-C2-1-P), and by the Santander Financial Institute are gratefully acknowledged. 


\section{Introduction}

As a source of exchange, innovation and creativity, cultural diversity is as necessary for humankind as biodiversity is for nature. UNESCO (2002), Article 1.

The present work deals with the issue of preserving language and cultural diversity in highly developed multilingual societies having two linguistically distan $\mathrm{t}^{2}$ official languages: $A$, denoting the language spoken by all individuals, and $B$, denoting the one spoken by a bilingual minority. Some examples of advanced multilingual societies with distant official languages and bilingual minorities are the Basque Country, Ireland and Wales. They are endowed with enough resources to design and implement well-articulated language policies in favour of $B$, which means, among other things, that they have a public bilingual educational system (see Mercator, 2008, 2014 , 2016), media, and markets for cultural goods related with language $B$. The idea is that these multilingual societies will set a kind of benchmark into the set of societies with threatened languages contemplated in Fishman (2001). The transmission of bilingual cultural traits in these multilingual societies works, fundamentally, through the public educational system (parents send their children to the public system to receive a bilingual education, so that they learn the two official languages $A$ and $B$ ). Thus, the institutions in charge of the cultural transmission generate a continuous flow of potentially bilingual individuals.

Cultural transmission was formally studied by Cavalli-Sforzza and Feldman (1981) by means of an evolutionary biology-based model, in a society with two cultural traits distributed in the population. Their model produces two stable equilibria, each allowing the survival of just one trait, and one unstable equilibrium where the two traits are present. Thus, the model did not capture well the diversity observed in certain societies, particularly in those with minoritarian cultural groups. Bisin and Verdier (2001, 2010), extended the Cavalli-Sforzza and Feldman model avoiding the boundary equilibria, and allowing for a stable interior equilibrium where the two traits can coexist in the population state. The present work adopts an evolutionary game-theoretic approach, free of biological constraints, to study the population dynamics of cultural traits represented by the two official languages, $A$ and $B^{3}$. However, we do not study language and culture transmission. Instead,

\footnotetext{
${ }^{2}$ See Ginsburgh and Weber (2011) for a survey on how to compute the distance between two languages; see also Desmet et al. (2009).

${ }^{3}$ We will model the population dynamics by means of the replicator dynamics. Even though the origin of the replicator equation is in biology (Maynard Smith, 1982), it has been shown that, in socio-economic contexts, it can be obtained from diverse trial-and-error learning procedures (see, among others, Binmore et al.,1995, Cabrales, 2000, Cabrales and Uriarte, 2013, and Schlag, 1998).
} 
we concentrate our analysis on the weakening of bilingual cultural traits that are observed in the data about the use of Basque, Irish and Welsh.

The data show that despite the existing proportions of speakers in those languages, the use of $B$ is lagging far behind. This seems to be a paradox in societies having a strong policy in favour of $B$. Why is it that having the political system - that is, elected governments promoting the use of $B$ - the legal instruments to facilitate its use $€^{4}$ resources, bilingual educational systems, and the bilinguals' preference for $B$, that the same people make a low use of $B$ ? Why is it that, knowing the Council of Europe's 5 advice that the key factor to avoid a minority language shift is that $B$ should be used in all social domains, speakers of $B$ often use $A$ when they interact between them, putting at risk the existence of $B$ and its related culture?

The purpose of this work is to analyse the source of this paradox which, adopting the Council of Europe's view, must be the process by which bilinguals decide the language to use in each interaction. Our view is that the survival of language $B$ depends, essentially, on the bilingual individuals, i.e. on how intense is their preference for using $B$ in their interactions.

Without denying the links with the cultural transmission literature, our work is closer to the literature about endangered minority languages and cultural diversity. This is a topic widely studied by sociolinguists (e.g. Fishman 1991, 2001; see a description of language death process in Crystal, 2000 ), and by physicists and mathematicians working in complex systems (Abrams and Strogatz, 2003 is the seminal work; see, among others, Stauffer and Schulze, 2005, Minett and Wang, 2008, Solé et al., 2010; this approach is surveyed in Patriarca et al., 2012). These two schools frame the process of threatening and eroding cultural diversity in the context of language competition dynamics. That is, natural languages, with their speech communities, are viewed as competing for speakers, very much like firms compete for market shares ${ }^{6}$. Surprisingly, this competitive situation has received little attention from economic theorists and from game theory practitioner:77. Our framework uses notions and analytical tools of behavioural economics, to study the language competition between $A$ and $B$, avoiding some undesirable features of both

\footnotetext{
${ }^{4}$ The Law of Normalisation of Basque's Use of 1982; the Welsh Language Measure of 2011; and the recognition by Constitution of the Republic of Ireland that Irish as the first official language.

${ }^{5}$ European Charter for Regional or Minority Languages www.coe.int/t/dg4/education/minlang

${ }^{6}$ As remarked by Nelde (1995) "neither contact nor conflict can occur between languages; they are conceivable only between speakers of languages and between the language communities".

7 "The lack of economic analysis of the natural language that characterizes human economic behaviour is certainly a large and visible hole". Anderlini and Felli (2004). Notable exceptions are Rubinstein (2000) and Selten and Pool (1991). Grin et al. (2010) and Ginsburgh and Weber (2011) are recent surveys of the research developed in the economics of language.
} 
sociolinguistics and the formal and complex systems approach. In sociolinguistics it is the lack of formalization that may help to throw light into the complexities of language competition. Physicists and mathematicians have yet to extend their models to allow for adaptive decision makers giving rise to more realistic population dynamics and behavioural results. These drawbacks are eluded by our model.

We highlight two factors that condition the bilinguals' language choices. One is the information that bilingual individuals have about the linguistic types (bilingual or monolingual) of the interactive partners. Very likely, that information was perfect in the past; in small, traditional communities with low immigration and mobility. However, in modern societies bilinguals are spread all over the country, particularly in urban areas ${ }^{8}$, where interactions are frequently anonymous, and the linguistic type tends to be private information. Thus, bilinguals must often choose the language of interaction without (perfect) information on the interlocutor's linguistic type. The other factor is that in these societies there is what is called a language contact situation (Nelde, 1995 and Winford, 2003) which means that the languages spoken by bilinguals are being altered, particularly $B$, due to the constant interaction between bilinguals and monolinguals using the majority language $A$.

We assume that bilinguals choose the language of interaction through an extended version of the Language Use Game (LUG) which is based on a game introduced by Iriberri and Uriarte (2012) (IU henceforth). The LUG is a game with imperfect information of linguistic types, in which bilinguals may choose between two pure strategies, either Reveal $(R)$ the bilingual type or Hide $(H)$ it. Imperfect information and language contact leave a tight room to satisfy the preference for the use of $B$. Under these circumstances, bilinguals are bound to make frequent language choices, giving rise to unconscious patterns of choice behaviour. Thus, we assume that the bilinguals play continuously the LUG, and learn by a trial-and-error adjustment process, modelled by the one-player replicator dynamics attached to the LUG. We show that this dynamic process converges into an interior evolutionary stable Nash equilibrium. This kind of equilibria are considered as conventions (Weibull, 1995). Therefore, in the context of the LUG, this equilibrium would be a linguistic convention in which the bilingual population is partitioned in two groups. One group is composed of those who choose $R$; they will always speak $B$ with any bilingual. The other group is composed by by those who choose $H$ : they speak $A$ between them. Thus, this equilibrium provides a theoretical explanation of the observed decline in the use of $B$. To test empirically this theory, we first make the Nash equilibrium to

\footnotetext{
${ }^{8}$ More than half of the Basque speakers live in the six most populated towns of the Country. Similarly, $75.7 \%$ of Welsh speakers live in towns of more than 100,000 inhabitants. Irish speakers outside the Gaeltacht are a minority, raised and educated through Irish, living in urban areas.
} 
depend on the proportion of bilinguals, $\alpha \in(0,1)$, and then we build econometric models that predict, for each $\alpha$, the rate of use of $B$ in equilibrium. Finally, the predictions are compared with the observed use of Basque, Irish, and Welsh. The main finding is that the predictions fit well the observed data. This is confirmed when testing them with nonparametric (i.e. model-free) data fits. Moreover, where data are available over time we see that the functions change quite smoothly.

The rest of the paper is structured as follows. In Section 2 we introduce the general framework of the LUG. Section 3 we extend the LUG introducing behavioural assumptions to build a Nash equilibrium function that depends on the proportion of bilingual speakers. In Section 4 we test the model for the Basque Country, Ireland and Wales. Section 5 concludes, summarizing results and pointing out policy measures. Section 6 contains the Appendix.

\section{The Theoretical Framework}

We will be dealing with economically advanced multilingual societies having two official languages, denoted $A$ and $B$. We assume that in those societies there are essentially two linguistic groups: the monolingual speakers, who speak only $A$, and a minority of bilingual speakers who speak, with similar skills, $A$ and $B^{9}$. Let $\alpha>0$ denote the proportion of bilingual speakers in the society, and $1-\alpha$ the proportion of monolinguals. We assume $\alpha<1-\alpha$, and $\alpha \in(0,1){ }^{10}$ The first assumption we make says that communication takes place in a single language, either $A$ or $B$.

A.1. The Languages with official status, $A$ and $B$, are linguistically distant so that successful communication is only possible when the interaction takes place in one language.

Individuals are therefore assumed to view $A$ and $B$ having the same status. We show below that A.1 is consistent with the data. Passive bilinguals, i.e. those who understand $B$ but cannot speak it, are, therefore, not considered (or can be treated as monolinguals; see empirical part). When a monolingual interacts with a bilingual, they necessarily use $A$. Thus, $B$ is spoken only if two bilinguals meet, and at least one signals the desire to speak in $B$. Hence, language choice is not trivial.

Some examples of societies with official languages satisfying A.1 are the Basque Country, Ireland and Wales. Basque is a pre-indoeuropean language in contact with the two Romance languages, Spanish (or Castellano) and French. Irish and Welsh,

\footnotetext{
${ }^{9}$ It should be clear from the outset that we are referring only to bilingual speakers in the two 'internal' official languages $A$ and $B$.

${ }^{10}$ The boundary numbers 0 and 1 are hardly representatives.
} 
two Celtic languages, are in contact with the Germanic language English. These are competitive multilingual societies, both in the economic domain, and in the linguistic domain, with sufficient resources to implement well articulated language policies to protect and transmit $B$ through the educational system. Thus, we will analyse theoretically and empirically the factors that might affect the use of $B$ in multilingual societies which are highly developed economically. Our view is that these societies form a kind of benchmark multilingual societies in the set of all societies with threatened languages satisfying A.1. If minority languages will be shifted there, this will even be more so in the less developed multilingual societies.

We may measure the use of $B$ in different ways. We can measure the frequency of use of $B$ (say, daily, weekly, less often, never) as it is done in the censi and surveys about the Irish and Welsh languages. Or we may measure the use of $B$ in the streets, as it is done for Basque. For Irish and Welsh we use observations about the Daily Use $(D U)$, for Basque we have the observations of Street Use $(K E)$; see Appendix 6.1 for details, and how $\alpha, K E$ and $D U$ are defined.

Table 1: Evolution of percentage of bilinguals $\alpha$ and Street Use or Daily Use for Basque, Irish and Welsh. For Basque, $\alpha$ and $K E$ was not always measured in the same year; e.g. 1991/3 indicates that $\alpha$ is from 91, $K E$ from 93. For Welsh, the surveys were executed over longer periods.

\begin{tabular}{lll|lll|lll}
\multicolumn{3}{c|}{ Basque } & \multicolumn{3}{c|}{ Irish } & \multicolumn{3}{c}{ Welsh } \\
\hline Year & $100 \alpha$ & $100 K E$ & Year & $100 \alpha$ & $100 D U$ & Years & $100 \alpha$ & $100 D U$ \\
\hline $1991 / 3$ & 22.3 & 11.8 & & & & & & \\
$1996 / 7$ & 24.4 & 13.0 & 1996 & 41.10 & 10.16 & & & \\
2001 & 25.4 & 13.3 & 2002 & 41.88 & 09.05 & & & \\
2006 & 25.7 & 13.7 & 2006 & 40.83 & 02.10 & $2004-06$ & 20.5 & 13.0 \\
2011 & 27.0 & 13.3 & 2011 & 40.60 & 02.15 & & & \\
2016 & 28.4 & 12.6 & & & & $2013-14$ & 19.0 & 10.1
\end{tabular}

Clearly, $K E$ and $D U$ will be modelled differently, but we suppose that both result from the same language game, and are functions of the same factors. Table 1 shows $\alpha, K E$ or $D U$, for the case of Basque, Irish, and Welsh for different years. Some features of the numbers are worth mentioning. While $\alpha$ is either steadily increasing (for Basque and Welsh) or on a very high level (Irish), the use of $B$ is lagging behind, stagnating or even going down. Note that we observe a structural break of $D U$ for Irish between 2002 and 2006. This may be due to the fact that only since 2006 the daily use of Irish is clearly defined as "used outside the education system". In Table 
1 only the aggregates are given; for the empirical study we will use the data taken on small area level exhibiting the joint variation of $\alpha$ and language use.

The bilingual population in each country displays an empirical regularity that is commonly observed in social groups: that the bilingual individuals tend to behave similarly (not identically, as we will see below in the equilibrium analysis of section 2.1.4) with respect to the use of language $B$. This universal regularity is, for Manski (1997), the result of a type of social process called anonymous endogenous interactions. It is a social process in which the behaviour of an individual varies with the distribution of behaviour in the reference group. The endogeneity of interactions will be formalized below by means of the replicator dynamics equation associated to the game played by the bilingual population.

\subsection{A Game- Theoretic Model of Language Choice}

We seek to understand the data of $B$ use. To this end, we model the strategic manner by which the members of bilingual population choose, at the beginning of an interaction, the language to use with the interactive partners. Bilinguals are assumed to choose only pure strategies, and adjust their choices endogenously by trial-and-error learning procedures. We will show that this adaptive process converges into a Nash equilibrium with the properties of a linguistic convention.

\subsubsection{Anonymous Interactions in Modern Multilingual Societies}

A feature of modern societies is the mobility, both social and geographical, of the work force. As a consequence, interactions become increasingly anonymous. In the benchmark multilingual societies, the spread of bilinguals across the layers of society would mean that frequently bilinguals participate in interactions without recognizing each other, because the linguistic types (bilingual or monolingual) have become private information 11 .

A key source of that imperfect information, that enhances the one derived from modernization, is the behaviour of the bilingual individuals themselves. For Nelde (1995) "contact between languages always involves an element of conflict". More specifically, if a monolingual is addressed in $B$, or observes an interactive partner who is signalling the desire to speak in $B$, then the monolingual is forced to reveal his type, and must confess his lack of knowledge of $B$. However, the need of communication will frustrate the bilingual's desire, who, by A.1, will also be forced

\footnotetext{
${ }^{11}$ In a very different context, but related with natural language issues, see how language competence is made private information in Blume and Board (2013).
} 
to switch, sometimes reluctantly, to $A$. This might create a tension between the interactants (not free of political undertones, in certain cases) that could interfere the final goal of the interaction. Thus, sending signals conveying the intention to speak in $B$ might be harmful for both sides ${ }^{12}$. Bilinguals experience frequently this kind of interaction. However, given their linguistic flexibility, a growing proportion of them tend to avoid the potential tensions with unknown interlocutors, and choose to speak $A$, mistakenly arguing that it is not polite to start with $B$ (see Amorrortu et al., 2009 for the case of Basque). Therefore, the politeness induced choice behaviour preserves the imperfect information about linguistic types. Further, this behaviour is reinforced if the probability of meeting a monolingual is much higher than meeting a bilingual; that is, because $1-\alpha>\alpha$.

We should also mention a new breed of bilinguals, called "new speakers", who have learnt the minority language by means other than the family transmission, essentially through immersion learning models in the educational system. These newcomers are inclined to deny themselves as "authentic" and legitimate speakers of $B$ as compared to the native speakers, even though they are fully competent in language $B$. They feel insecure with $B$, and tend to not use it outside the school, thus, hiding their bilingual type to interlocutors. See Ortega and al. (2015) for Basque, O'Rourke and Ramallo (2011) for Irish, and Selleck (2018), for Welsh.

Additional sources of anonymity, among others, are: (a) the continuous contact and interaction with speakers of language $A$ erase some revealing signals of $B$ speakers, such as the accents. The contact situation makes both bilinguals and monolinguals to have a similar accent, which is shaped by the dominant language ${ }^{13}$, (b) Second and third generations of immigrants learn language $B$ in the public educational system. Thus, differences in ethnic features, if any, hardly reveal the linguistic type. Thus the anonymity of interactions is the result of a combination of several sources. We are then led to conclude that it is realistic to assume that in the benchmark multilingual societies linguistic types are, often, private information ${ }^{14}$.

A.2. Imperfect information: The participants of an interaction do not have, ex-ante, any information about the linguistic type (bilingual or monolingual) of each other. They only know the average proportion of bilingual and monolingual speakers,

\footnotetext{
${ }^{12}$ We could observe the subtleties of this potential conflict by means of linguistic politeness theory (see Brown and Levinson, 1987). For a detailed discussion on this, see Uriarte (2017).

${ }^{13}$ For example, in the Spanish side of the Basque Country, bilingual and monolingual people have similar Spanish accent, while in the French side they have a French accent.

${ }^{14}$ To avoid this, Welsh speakers may wear the Cymraeg badges of the Welsh Language Comission. There are also badges for Welsh learners, as well as lanyards and email footer, etc. This does not exist in the Basque Country, probably because it would be politically controversial. Signs announcing that Basque is spoken in official buildings, banks and shops are fairly common though.
} 
$\alpha$ and $(1-\alpha)$ respectively, of the society and that $0<\alpha<(1-\alpha) \cdot{ }^{15}$

Remark: One may argue that it is very likely that the street use of $B$ occurs also in assortative matching. But any econometric model (such as the ones we estimate later) is a trade-off between a simplifying economic model and reality. We may account for assortative matchings by introducing a parameter $p$ denoting the proportion of random matches and $1-p$ that of assortative matchings of bilinguals. We did this in an earlier version of the work, but the additional parameter $p$ did neither lead to deeper insights nor to better fit: ${ }^{16}$.

\subsubsection{Linguistic Preferences and Payoffs}

The fact that language $B$ has become official reflects not only that linguistic rights of the minority language speakers are respected, but also that bilinguals manifest a preference for communication in language $B$. We may assume that this linguistic preference could be weighted by a proper choice of payoffs. Payoffs are assumed to represent net communication benefits (see Selten and Pool, 1991, and Selten and Warglien, 2007). A monolingual speaker cannot make language choices; thus, assuming that every individual has the same language competence and communication skills in $A$, a monolingual speaker will get a sure payoff $n$. Since language choices are made under imperfect information, a bilingual may choose voluntarily language $A$. In that case, we assume that he gets the payoff $n$. Bilingual speakers will get the maximum payoff, $m$, when they coordinate in their preferred language $B$. However, $(n-c)>0$ would be the payoff to a bilingual speaker who, having chosen $B$, is matched to a monolingual, and therefore is forced to switch to $A$. Then $c$ denotes the frustration cost. In sum:

A.3. Language preferences and Payoffs: bilingual speakers prefer to use language $B$. Further, it holds $m>n>c>0$, and that the frustration cost is smaller than the weighted benefits, i.e. $c<(m-n) \frac{\alpha}{(1-\alpha)}=b(\alpha)$.

\footnotetext{
${ }^{15}$ We assume that bilinguals know the average proportion $\alpha$ of bilinguals in the society because a summary of sociolinguistic statistics are periodically published, and talked about in the media. Note that Catalan is a minority language inside the Spanish State, but inside Catalunya, out of a population of 7,496,27, roughly $\alpha=76 \%$ speak Catalan and $86 \%$ understand it. Further, since A.1 is not satisfied between Castellano and Catalan, and there is common knowledge that 'almost' all individuals speak or understand Catalan, there is no hindering of the flow of a conversation nor any tension caused by starting in Catalan with unknown interlocutors. Hence, neither A.1 nor A.2 apply. Similarly, the theories developed for Catalan would not apply here, see IDESCAT.

${ }^{16}$ Say, by introducing the parameter $p$, the empirical Model 2, that predicts the street use of $\mathrm{B}$, described below, would be $p \alpha^{2}\left(x^{*}\right)^{2}+(1-p) \alpha^{2}$.
} 


\subsubsection{The Language Use Game (LUG)}

Under the assumptions A1-A.3, bilinguals, at the beginning of an interaction, may take a decision about the language to be used in the interaction. An ordinary conversation has a sequential nature. Therefore, the choice of language is better described by a game in extensive form, such as the game of IU (Iriberri and Uriarte, 2012). For empirical purposes we present now its strategic form (which will be extended in Section 3). Under the assumptions A.1-A.3, the bilinguals' language strategic behaviour is captured by the following pure strategies of bilinguals:

R: Reveal always your type, so that you will speak $B$ whenever you meet a bilingual.

$\mathbf{H}$ : Hide your type, and reveal it only when matched with an R-player. That is, speak $A$, and switch to $B$ only when you are addressed in $B$.

IU show the sequential nature of these two strategies. As a speaker (i.e. as the interactant who starts the conversation) or as listener (i.e. the one who comes after the speaker) an $R$ chooser will try to use $B$ (sending signals of wanting to use $B$ ) to discover the interlocutor's linguistic type, so that $B$ will be used when he meets another bilingual ${ }^{17}$. In this event he will get the maximum pay-off $m$; but in the event of meeting a monolingual he gets $(n-c)$. An $H$ player will choose $A$ in the role of speaker. Whereas, as a listener, he will answer in the language used by the speaker, either $A$ or $B$. Therefore an $H$ chooser avoids the cost $c$, and when he meets an $R$ chooser he will get $m$. The essence of $H$ is that it reinforces the imperfect information. When two bilinguals who choose $H$ meet, they will speak in $A$. Language $B$ will be spoken whenever two bilinguals meet, and, at least, one of them chooses $R$. An $H$ chooser behaves like a monolingual in disguise unless he is discovered by an $R$ chooser. Clearly $H$ is less demanding than $R$ (recall the arguments for the imperfect information assumptions).

There are two states of nature: Bilingual and Monolingual. When the Bilingual state is realized, two bilingual agents meet and play the game described by the twoby-two matrix on the left side of Figure 1. Each cell in this matrix lists the pay-off to the row and column players in lower case letters ( $m$ or $n)$, and, for each strategy combination, the resulting language of the interaction, shown in capital letters $(A$ or $B$ ). When the Monolingual state is realized the bilingual meets a monolingual and, depending on the strategy chosen, gets the pay-off shown by the column on the right side of Figure 1 . In this state, the language of conversation is $A$, regardless of the bilingual's strategy. ${ }^{18}$ At the start of the game a state is realized. Bilinguals do

\footnotetext{
${ }^{17}$ When an interlocutor is addressed in $B$, he would feel forced, by $\mathbf{A . 1}$ and $\mathbf{A . 3}$, to confess his linguistic type (monolingual or bilingual). A monolingual might feel unconfortable in this situation.

${ }^{18}$ We skip the matching of two monolingual speakers since it is irrelevant, and only show the
} 
not know the state when they choose a pure strategy. They hold beliefs assigning probability $\alpha$ to the state Bilingual and probability $1-\alpha$ to the state Monolingual. Therefore, a bilingual expects to meet another bilingual with probability $\alpha$, and a monolingual speaker with probability $1-\alpha$. This comes from assumption A.2.

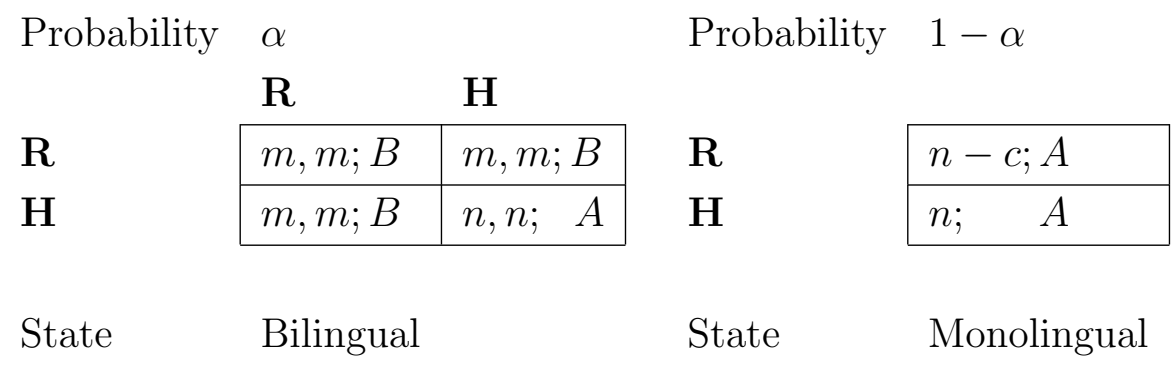

Figure 1: The Language Use Game.

\subsubsection{The Language Use Game as a Population Game}

Assumptions A.1 and A.2 joint with the close contact with monolinguals capture the conditions under which bilinguals must make their language choices. Then the bilinguals' linguistic preferences (A.3) lead them to make frequent language choices, aiming to get an efficient communication and the coordination in their preferred language $B$. Theoretically, we may view the LUG not as a one-shot game, but as a game played continuously by bilinguals.19 In this manner, we have converted the LUG into a game played by the bilingual population.

Bilinguals learn by a trial-and-error adjustment process, based on imitation and interactive learning (i.e. endogenous interactions). At each moment of time there is a population state $\left(N_{R} / N, N_{H} / N\right)$, where $N$ denotes the total number of bilinguals (we suppress time in the notation), and $N_{i} / N$ represents the share of bilinguals playing pure strategy $i,(i=R, H)$. The continuous play of the LUG produce changes in the population state and in the payoffs to the pure strategies, resulting in a population dynamics in continuous time, the one-player population replicator dynamics attached to the LUG (see Appendix 6.2). The replicators are the pure strategies $R$ and $H$. This version of the replicator dynamics assumes that bilinguals will choose only pure strategies. Let $x$ denote the proportion of bilingual speakers who choose to play $R$. Under A.1-A.3, and a given $\alpha \in(0,1)$, the bilingual player population's adjustment process converges into the unique evolutionary stable equilibrium

bilingual's payoffs. When looking at the language use data, the matches of monolinguals are taken into account, as they are a part of our observations.

${ }^{19}$ The game is played through pairwise random matches. That is, pairs of individuals are repeatedly drawn at random to play the game through which the language of interaction is determined. 
of the LUG, denoted $x^{*}$. This is the only asymptotically stable equilibrium in the associated one-population replicator dynamics:

$$
x^{*}=1-\frac{(1-\alpha) c}{\alpha(m-n)}, x^{*} \in(0,1) .
$$

There are two additional Nash equilibria, $(R, H)$ and $(H, R)$, both unstable, and the language of interaction in both equilibria is $B$, see also Appendix 6.2.

In social or economic contexts, an evolutionary stable equilibrium, such as $x^{*}$, can be thought of as a convention (Weibull, 1995). Thus, the population dynamics attached to the LUG converges into a linguistic convention. ${ }^{20}$ This linguistic convention takes the form of a partition of the bilingual population in two groups. The group $N x^{*}=N_{R}^{*}$ consists of all the bilinguals who have chosen the pure strategy $R$ in equilibrium. The other group, $N\left(1-x^{*}\right)=N_{H}^{*}$, consists of all the bilinguals who have chosen the pure strategy $H$ in equilibrium ${ }^{21}$

Any member of $N_{R}^{*}$ will speak in $B$ whenever he meets a bilingual. However, when a bilingual of the group $N_{H}^{*}$ meets another bilingual of the same group, they will speak in $A$. They will use $B$ only when they encounter a bilingual of the $N_{R}^{*}$ group. The theoretical finding is described in the following proposition:

Proposition: Under the assumptions A1-A.3, and the exogenously given parameters $\alpha \in(0,1), m, n$ and $c$, the population dynamics (or equivalently, the language use population dynamics) attached to the LUG converges into an evolutionary stable mixed strategy Nash equilibrium, $\left(x^{*}, 1-x^{*}\right)=\left(N_{R}^{*} / N, N_{H}^{*} / N\right)$. This equilibrium is a linguistic convention which, since $x^{*}>0$, includes a degree of erosion in the use of $B$ : the smaller the value of $x^{*}$, the higher the matching probability $\left(1-x^{*}\right)\left(1-x^{*}\right)$ of two bilinguals who have shifted to speak $A$.

According to this Proposition, the observed low levels of language $B$ use could be theoretically explained by a convention with a relatively high proportion of bilinguals choosing $H$ in equilibrium, $1-x^{*}$. It may happen that, for values of $x^{*} \in(0,0.293)$, the matching probability between bilinguals who will use $A$ will be higher than the matching probability of bilinguals who will use $B:\left(1-x^{*}\right)\left(1-x^{*}\right)>x^{*} \times x^{*}+x^{*}(1-$ $\left.x^{*}\right)+\left(1-x^{*}\right) x^{*}$. As any other convention (Young, 1995), the linguistic one, will become a self-enforcing mechanism of language coordination, hard to remove, which could extend to domains where information is not private, such as family, friends,

\footnotetext{
${ }^{20}$ The one-shot play analysis of standard game theory will not capture the strong stability features of $x^{*}$ which are relevant in our analysis.

${ }^{21}$ Hence, the equilibrium $\left(x^{*}, 1-x^{*}\right)$, instead of being interpreted as a randomization performed by each and every bilingual, it is interpreted as a population state $\left(N_{R}^{*} / N, N_{H}^{*} / N\right)$. They are both equivalent; see Weibull (1995).
} 
and assortative matching:22, The strong stability properties of $x^{*}$ allow us to make the following hypothesis to understand the use of $B$ reflected in the data:

Hypothesis 1 . For a given proportion of bilinguals $\alpha \in(0,1)$, and payoffs $m, n$ and $c$, the evolutionary stable mixed strategy Nash equilibrium $x^{*}$ could be thought of as a theoretical representation (that is, a model) of the fraction of bilingual speakers who, in real-life-situations, use language $B$ whenever they meet a bilingual.

We have data about the precise proportions of those who have the knowledge of Basque, Irish, and Welsh, the $\alpha$ proportions. We also have observations of the measures of actual use of $B$. To test empirically the validity of this hypothesis, we build the function $x^{*}(\alpha)$ that tells us the evolutionary stable Nash equilibrium associated to each $\alpha \in(0,1){ }^{23}$ Based on $x^{*}(\alpha)$, we, then build empirical models which will predict the street and daily use of $B$ of equilibrium. We test the validity of the hypothesis by studying how good those predictions fit the observed data. ${ }^{24}$

\section{A Behavioural Theory for the Nash Equilib- rium Function}

To build the Nash equilibrium function $x^{*}(\alpha)$ we need to develop a theory which would convert (1) into an econometric model from which one can estimate empirical predictive models. But notice that $x^{*}$ is obtained for a given $\alpha$ and constant $m, n$ and $c$. One can easily argue and empirically show that this is too strict for being considered a realistic model. To prove this, we have made elsewhere the exercise of predicting the use of $B$ based on the model of $x^{*}$ with $m, n$ and $c$ constant. We show that the model adapts badly to all observed data, and was rejected throughout by nonparametric tests. Furthermore, for $m, n$ and $c$ constant, $x^{*}(\alpha)$ is a strictly increasing and concave function that can hardly be justified by economic theory. So we need to take care of the parameters $m, n$ and $c .25$

\footnotetext{
${ }^{22}$ The following comments of the Secretary of Linguistic Policy for Basque, after the $V$ Sociolinguistic Survey, are relevant: "In the last twenty years the use of Basque in the family has decreased one per cent." Baztarrika (2014). For the Surveys of Basque, see Appendix 6.1.

${ }^{23}$ You may consider $\alpha$ as an exogenous variable because its changes are mainly due to factors related to cultural identity, and the responsibility in transmitting the language to future generations. The existence of a public bilingual educational system produces a continuous flow of bilinguals that changes $\alpha$. This means that the Selten and Pool (1991)'s argument of communicative benefits as the driving force to invest in the learning of a language hardly applies here.

${ }^{24}$ Note that $x^{*}(\alpha)$ and the predicting functions of language $B$-use, called $P K E(\alpha)$ and $P D U(\alpha)$ below, are not the same. You can only identify and estimate $\operatorname{PKE}(\alpha)$ and $P D U(\alpha)$, not $x^{*}(\alpha)$.

${ }^{25}$ Since there are no data that allow to test some of the arguments we will use in the following, one can only test the finally resulting model. This is a problem shared by probably all papers
} 
Notice that one can think of $n$ as the natural pay-off level get by monolinguals, and by the bilinguals who voluntarily choose language $A$. Therefore, we may assume that $n$ is not sensitive to $\alpha$, and limit to the modelling of $m$ and $c$.

The theory for $x^{*}(\alpha)$ is based on Kahneman and Tversky (1979)'s psychological reference point, which is a cornerstone in behavioural economics. Bilinguals may have different views and expectations about factors that might affect the status of the minority language. They would assign different probabilities to the event of, say, language shift, they may also have different views about when $B$ is out of danger, or when a bilingual society is achieved ${ }^{26}$ They may also differ on how much their experienced utility 27 (see Kahneman et al., 1997) is increased when coordinating in $B$, that is, $m$, and on the loss of utility when forced to switch to $A$, that is, $c$. Our view is that all the differences in perceptions and expectations bilingual individuals might have, are conditioned by the differences in the sociolinguistic contexts in which they are immersed. By sociolinguistic context we refer to an area with a specific proportion of bilinguals, and thus a certain presence of language $B$ in the workplace, streets, etc. (each context has a linguistic landscape; see Landry and Bourhis, 1997) which clearly depends on $\alpha$. For instance, the sociolinguistic context of the heavily industrialized metropolitan area of Bilbao (23\% of Basque speakers and a $K E$ of $2.5 \%$ ) is quite different from that of, say, San Sebastian-Donostia (with $40.6 \%$ and $15.2 \%$, respectively). The same applies to the context of Dublin city and suburbs (32.8.2\% of Irish speakers, and a $D U$ of $1.3 \%$ ) relative to the towns and villages of the Gaeltacht areas, such as Galway and suburbs (41.4\%, and 3\%, respectively). Similarly, Cardiff (11.0\% and 4.86\%, respectively) relative to Gwynedd (66.75\% and $66.75 \%$, respectively). It would be highly unrealistic to assume that $m$ and $c$, are not sensitive to the sociolinguistic contexts, i.e. to changes in $\alpha$; or, equivalently, that they are the same in different municipalities and areas with different $\alpha$.

Our theory assumes that each bilingual individual is adapted to some sociolinguistic context of $B$ in relation to $A$, in the context of a globalised society. The intuition is based on a basic tenet of Kahneman and Tversky (1979): "Our perceptual apparatus is attuned to the evaluation of changes or differences rather than to the evaluation of absolute magnitudes. When we respond to attributes such as brightness, loudness, or temperature, the past and present context of experience defines an adaptation level, or reference point, and stimuli are perceived in relation to reference point [...].

testing economic theory with data. The best we can do here is to develop a theory based on stylized facts, and fundamental concepts of behavioural economics.

${ }^{26}$ By bilingual society we mean a society where almost all individuals speak or at least understand $A$ and $B$, and the obstacles to use $B$ are removed.

${ }^{27}$ That is, the hedonic experience associated with speaking $B$ or the painful experience of being forced to use $A$. Henceforth, we will use indistinctly 'experienced utility' and 'utility'. 
Thus, an object at a given temperature may be experienced as hot or cold to the touch depending on the temperature to which one has adapted. The same principle applies to non-sensory attributes such as health, prestige, and wealth."

We apply this idea to the perception of bilinguals about the minority language $B$. In a language contact context, the frequency with which a bilingual experiences meeting another bilingual in the past determines an adaptation level or reference point. This adaptation conditions the bilingual's expectations of the same event in the future, and of the status of $B$. It will condition too his experienced utility of speaking $B$. Each sociolinguistic context will shape a specific reference point for him. Thus, the bilinguals' similarity of behaviour is sociolinguistic context dependent.

Where $\alpha$ is high, the event of two bilinguals matching and speaking in $B$ is fairly frequent. In those contexts bilinguals will be adapted to that frequency. If $B$ is the dominant language of communication of a sociolinguistic context, the utility bilinguals experience cannot be far from the payoff $n$, i.e. bilinguals' utility $m$ would be near $n$. Equivalently, in that sociolinguistic contexts the bilingual would not suffer a perceptible utility loss due to being forced to use $A$ when meeting, eventually, a monolingual. That is, we would assume that then $c$ would be 'almost' zero.

In general, speakers of a minority language in a contact situation, satisfying A.1, tend to feel a certain level of latent frustration caused by the permanent difficulties of keeping the language alive. When the proportion of bilinguals is low, the probability of matching between bilinguals is low, and so the probability of speaking in $B$ could even be smaller. The bilinguals of that kind of context would be adapted to those frequencies. The lack of use of $B$, and the overwhelming presence of $A$, induce some individuals to loose language skills and competence in $B$. But others will try to escape by building ways to meet other bilinguals and satisfy their wish of speaking $B$. So they make the effort of creating clubs of $B$ speakers, spend personal time and effort for organising activities in their leisure time (music gigs, drama productions, talks, sports, language teaching for adults, and other events), just for the pleasure of speaking $B$, and feeling that they are part of a cultural identity ${ }^{28}$. Clearly, the experienced utility felt by these bilinguals when they speak $B$ must be high.

If we take into account different municipalities or areas of the countries or regions under study, we get a rich set of values of $\alpha$, representing the variety of sociolinguistic contexts for $B$; that is, we assume $\alpha \in(0,1) .29$ We summarize the above as follows:

\footnotetext{
${ }^{28}$ These types of clubs abound in the countries under study. In the Basque Country they take the name of Mintzalagunak "Speak with Friends"; in Ireland are called Na Gaeil Óga GAA Club; and in Wales Mentrau Iaith Cymru.

${ }^{29} \mathrm{We}$ take the open unit interval $(0,1)$ as representing all the variety of sociolinguistic contexts of the country.
} 
Let $\alpha_{L}^{*} \in(0,1)$ denote a hypothetical proportion of bilinguals which the present bilinguals of the sociolinguistic context $\mathrm{L}$ think it would convert $\mathrm{L}$ into a bilingual society 30 . Thus, $\alpha_{L}^{*}$ represents the aspiration for the bilinguals of $\mathrm{L}^{31}$,

A.4. Let $S\left(\alpha_{L}\right)=\alpha_{L}^{*}$ be the function that describes how the bilinguals of context $L$ determine their aspiration $\alpha_{L}^{*}$, given the present $\alpha_{L}$ to which they are adapted to $\left(1>\alpha_{L}^{*}>\alpha_{L}>0\right)$. We assume that $S$ is a continuous, concave, and strictly increasing function in $\alpha$.

Remark: Since aspiration levels will differ due to the heterogeneity of sociolinguistic contexts, we can assume that the distance between the smallest aspiration level $\alpha_{\underline{L}}^{*}$ and the highest one $\alpha_{\bar{L}}^{*}$ is small ${ }^{32}$. Then we choose the highest one to represent the aspiration level of the whole bilingual population, and denote it as $\alpha^{*}<1$. It may happen that for a small community of bilinguals of some area $L, \alpha^{*}$ is infeasible or out of reach, due to the cultural and sociological constraints of that area. It is well known experimentally and theoretically, that unavailable choices have an important influence on the decision behaviour of agents, known as aspiration effects (Begum et al. 2016, and Begum and Richter, 2015). The higher the distance between the actual $\alpha_{L}$ and $\alpha^{*}$, the higher the aspiration effect. Then $B$ would be perceived in a more intense way in contexts with low presence of bilinguals, and some of them would volunteer to do extra work to save the language in this area (as observed).

A.5. The experienced utility of speaking language $B$, is a real valued continuous function, denoted $m(\alpha)$, that strictly decreases with $\alpha$. As a tends to the bilinguals' aspiration $\alpha^{*}, m(\alpha)$ tends to the "natural" pay-off level $n 2^{33}$

The latent frustration mentioned above becomes explicit when the bilingual meets a monolingual. When this occurs, the level of frustration felt will depend on the proportion $\alpha$, which is the reference proportion or adaptation level for that bilingual. We denote the (explicit) frustration felt in that matching as $c(\alpha)$. The reasons given above lead us to make the following assumption.

A.6. The frustration cost of being forced to use $A$ is a real valued continuous function, denoted $c(\alpha)$, that strictly decreases in $\alpha$.

\footnotetext{
${ }^{30}$ That is, a place, where there would be 'almost' no obstacles to the social use of $B$. It should not be a forecast based on sophisticated techniques. It could only be a projection of desires to overcome the difficulties faced by language $B$ in the present.

${ }^{31}$ In a choice problem, the aspiration represents the most desired alternative, available or not. Hence, at $\alpha_{L}^{*}$ the bilinguals, with context L's preferences, feel satisfied.

${ }^{32}$ That is, $\left|\alpha_{\bar{L}}^{*}-\alpha_{\underline{L}}^{*}\right| \leq \varepsilon$, for $\varepsilon>0$ small. This would imply a extreme concave curvature of the $S$ function,

${ }^{33}$ Most likely, there would be a small interval of low levels of $\alpha>0$, in which $m$ will be increasing in that interval. But for the greatest part in the domain of $\alpha \in(0,1), m(\alpha)$ is monotonically decreasing. Nothing relevant is lost by keeping A.5 as it is.
} 


\section{The econometric models}

The next step is to apply A.1-A.6 for building an econometric model which we can be used for testing our model along the observed data. We first specify $x^{*}$ to construct predictors for the expected $K E$ and $D U$ along our theory model.

\subsection{From Nash equilibrium function to language use models}

We complete the building of $x^{*}$ as a function of $\alpha$ by specifying $m$ and $c$ as simple functions satisfying A.4-A.6. Let us suppose that $m(\alpha)$ is a simple decreasing function of type $\frac{K}{\alpha}$, where $K>0$ is a constant. For any $\alpha<\alpha^{*}$ we get $m(\alpha)>n$ such that a bilingual speaker get a positive profit whenever he coordinates in $B$. Profits would be zero when the language is normalized, in the sense $m\left(\alpha^{*}\right)=\frac{K}{\alpha^{*}}=n$. Then for $\alpha<\alpha^{*}<1$, and a given value of $n$, we get $K=\alpha^{*} n<n$, and so the weighted profit $b(\alpha)=(m(\alpha)-n) \frac{\alpha}{(1-\alpha)}$ is a decreasing function.

Assumption A.3 reads now as follows: for any $\alpha<\alpha^{*}$, the frustration cost function is strictly smaller than the weighted benefit function:

$$
c(\alpha)<(m(\alpha)-n) \frac{\alpha}{1-\alpha}
$$

This condition allows the use of language $B$ in equilibrium (IU). Then

$$
c(\alpha)=(m(\alpha)-n) \frac{\alpha}{(1-\alpha)}-\tilde{b}(\alpha)
$$

for some $\tilde{b}(\alpha)>0$ denoting the net benefit. Inserting equation (2) in $(1)$ we obtain

$$
x^{*}(\alpha)=\frac{\alpha(m(\alpha)-n)-c(\alpha)(1-\alpha)}{\alpha(m(\alpha)-n)}=\frac{\tilde{b}(\alpha)(1-\alpha)}{\alpha(m(\alpha)-n)},
$$

and substituting $m(\alpha)=\frac{K}{\alpha}$ gives

$$
x^{*}(\alpha)=\frac{\tilde{b}(\alpha)(1-\alpha)}{K-n \alpha} .
$$

Equation (3) shows how the predicted equilibrium proportion of the bilingual population playing $R$ changes with $\alpha$. The denominator is positive because $m(\alpha)=\frac{K}{\alpha}>$ $n$ for all $0<\alpha<\alpha^{*}$. Hence $x^{*}=x^{*}(\alpha)>0$, and it is increasing in $\alpha$ if $\tilde{b}(\alpha)$ is not decreasing faster than $\frac{1-\alpha}{\alpha(m(\alpha)-n)}$ is increasing ${ }^{34}$ So one would assume that the net benefit function $\tilde{b}(\alpha)$ has a well defined first derivative. Finally, let $\breve{b}:=\tilde{b} / n$

\footnotetext{
${ }^{34}$ The first derivative of $g(\alpha)=\frac{1-\alpha}{\alpha(m(\alpha)-n)}$ with respect to $\alpha$ is $g^{\prime}(\alpha)=\frac{n-K}{(K-n \alpha)^{2}}$. Hence, for $\alpha<\alpha^{*}<1, g^{\prime}(\alpha)>0$ since $K=\alpha^{*} n<n$.
} 
denote the relative net benefit (recall, $n$ is constant). Substituting $K=n \alpha^{*}$ in the denominator of (3), we get

$$
x^{*}(\alpha)=\frac{\breve{b}(\alpha)(1-\alpha)}{\left(\alpha^{*}-\alpha\right)} .
$$

Since $x^{*}(\alpha)$ is an interior equilibrium, that is, $x^{*}(\alpha) \in(0,1)$, we have $\check{b}(\alpha)(1-\alpha)<$ $\left(\alpha^{*}-\alpha\right)$, where $1>\alpha^{*}>\alpha>0$, and hence $0<\check{b}(\alpha)<1$.

We capture A.6 with the specification $\check{b}(\alpha)=\beta_{1}\left(\alpha^{*}-\alpha\right)^{\beta_{2}}$ for unknown $\beta_{1}, \beta_{2}$. We specify $\alpha^{*}=\alpha^{\beta_{3}}$ for unknown $\beta_{3}$. For the model to make sense, we work with restrictions $\beta_{1}>0$ and $0<\beta_{3}<1$. Then (4) is converted into

$$
x^{*}(\alpha)=\beta_{1}(1-\alpha)\left(\alpha^{\beta_{3}}-\alpha\right)^{\beta_{2}-1} .
$$

As mentioned, our data of use, $K E$ and $D U$, refer to different things: street use and daily use, respectively. This requires different modelling for $K E$ and $D U$, the former being more challenging, as we will see.

Model 1: Having in mind (1), the model of expected $K E$ is obtained by looking at the probabilities of random matches of bilinguals (if a monolingual is involved, $A$ is used anyhow) in which an $R$ player does participate. That is, the probability of a random match where an $R$ player meets another $R$ player $\left(\alpha^{2} x^{* 2}\right)$, plus the probability that an $R$ addresses an $H$ player $\left(\alpha^{2} x^{*}\left(1-x^{*}\right)\right)$, plus the probability that an $H$ addresses an $R$ player $\left(\alpha^{2}\left(1-x^{*}\right) x^{*}\right)$. In sum,

$$
E\left[K E \mid \alpha, x^{*}\right]=\alpha^{2}\left(2 x^{*}-x^{* 2}\right) .
$$

This is the result of an $R$ player who takes the role of leader (as a speaker or as a responder) in the language $B$ coordination process. When he meets a bilingual, then they speak in $B$. An $R$ player will lead the coordination process in any player role or position (row or column) in the game. Let us call him strong $R$-player.

In real life however, we find bilinguals who sometimes lead the language $B$ coordination process, and sometimes are led. The reason is because bilinguals are aware that, in order to satisfy their preference for the use of $B$ requires being always the leader in the coordination. But that role is very demanding. As mentioned, $R$ is a risky choice since you may suffer a frustration if you meet a monolingual, and thus, get the minimum payoff, $n-c$. Further you may upset the monolingual and introduce tension in the dialog alignment. It is natural then that a bilingual will try to avoid being seen as rude or impolite. We should also have in mind that any bilingual has a prior information about the rates of failure and success in the coordination in $B$. That personal experience will shape his actual behaviour, which moves him to be 
more flexible, combining the $R$ and $H$ strategies. Thus, in practise, the following model might be more realistic.

Model 2: Without loss of generality, we assume that in $50 \%$ of all his conversations the bilingual starts the conversation. He certainly does so in $B$. The other $50 \%$ are started by the other person, and he answers in whatever language is used by the first speaker. We may call this bilingual a weak $R$-player.

The resulting expected $K E$ is the sum of the probability of a random match where an $R$ player meets another $R$-player $\left(\alpha^{2} x^{* 2}\right)$, plus the probability that an $R$-player addresses an $H$ player $\left(\alpha^{2} x^{*}\left(1-x^{*}\right)\right)$, i.e.

$$
E\left[K E \mid \alpha, x^{*}\right]=\alpha^{2} x^{* 2}+\alpha^{2} x^{*}\left(1-x^{*}\right)=\alpha^{2} x^{*} .
$$

Model 3: For modelling the expected daily use, $D U$, it is assumed that almost all individuals that play strategy $R$ will answer (in the census or survey) that they use $B$ every day, whereas almost all individuals playing strategy $H$ will answer that they do not. Deviations from these rule should cancel out in average. Consequently, the expected $D U$ is simply

$$
E\left[D U \mid \alpha, x^{*}\right]=\alpha x^{*}
$$

We propose the following theory models:

Hypothesis 2. Let $\alpha$ denote the proportion of bilingual speakers in a certain sociolinguistic context. Then

Model 1: $P K E_{1}(\alpha)=\alpha^{2}\left(2 x^{*}-x^{* 2}\right)$ is the predicted street use of $B$ in that context if the choosers of the $R$ strategy are strong.

Model 2: $P K E_{2}(\alpha)=\alpha^{2} x^{*}$ is the predicted street use of $B$ if the choosers of $R$ are weak.

Model 3: $P D U(\alpha)=\alpha x^{*}$ is the predicted daily use.

Note that, as already indicated, the data allow us to test our hypothesis (say, Propositions 1 and 2) only as a whole, not separately.

Using (5), we substitute $x^{*}$ in the three models, and get:

$$
\begin{aligned}
P K E_{1}(\alpha) & =\alpha^{2}\left\{2 \beta_{1}(1-\alpha)\left(\alpha^{\beta_{3}}-\alpha\right)^{\beta_{2}-1}-\left(\beta_{1}(1-\alpha)\left(\alpha^{\beta_{3}}-\alpha\right)^{\beta_{2}-1}\right)^{2}\right\} \\
P K E_{2}(\alpha) & =\alpha^{2} \beta_{1}(1-\alpha)\left(\alpha^{\beta_{3}}-\alpha\right)^{\beta_{2}-1} \\
\operatorname{PDU}(\alpha) & =\alpha \beta_{1}(1-\alpha)\left(\alpha^{\beta_{3}}-\alpha\right)^{\beta_{2}-1}
\end{aligned}
$$


These are the models we will study empirically for Basque, Irish and Welsh. In order to estimate them from the samples $\left\{K E_{c t i}, \alpha_{c t i}\right\}_{i=1}^{n_{c t}},\left\{D U_{c t i}, \alpha_{c t i}\right\}_{i=1}^{n_{c t}}$ for language sample $c$ in year $t$ one might consider either

$$
K E_{c t i}=P K E_{c t i}+\varepsilon_{c t i}, \quad D U_{c t i}=P D U_{c t i}+\epsilon_{c t i}
$$

(and analogously for $D U$ ) or, as a model with multiplicative structure,

$$
\log \left(K E_{c t i}\right)=\log \left(P K E_{c t i}\right)+\tilde{\varepsilon}_{c t i}, \quad \log \left(D U_{c t i}\right)=\log \left(P D U_{c t i}\right)+\tilde{\epsilon}_{c t i} .
$$

This is done by least squares under the constraints that $\beta_{1}>0$ and $0<\beta_{3}<1$. Note that models $(12)$ and (13) require different assumptions on the (random) deviations from the mean. They are, however, not testable, so that we have no particular a priori preference. While the general findings are quite similar resulting from one or the other estimation strategy, predicting the language use from the logarithmic version (and consequently $\widehat{\log (K E})$ or $\widehat{\log (D U})$ ) is somewhat more complex as one has to correct for the - in our case heteroscedastic - error dispersion since $E[\log (K E) \mid \alpha]<\log E[K E \mid \alpha] ;$ the same holds certainly for $D U$. Also, the data fits when looking at the untransformed data did not look very convincing. We therefore give the least square estimates resulting from model (12). All estimates are given together with nonparametric fits of $K E(D U)$ on $\alpha$ using local linear estimators and local bandwidth ${ }^{35}$ with Epanechnikov kernel; see Appendix for details.

\subsection{Empirical Results}

The presentation of results concentrates on the predictive functions, as these are in the centre of our interest. The parameters have no interesting interpretation, and are therefore deferred to the Appendix 6.3 and 6.4. While the $99 \%$ confidence bands of the functions are very narrow, the $95 \%$ confidence intervals for the parameter estimates are quite wide due to extremely high correlations (not shown) between the parameter estimates. These, like standard errors and the p-values of our test, are estimated by wild bootstrap. In Figures 2 to 4 the thick solid line is the model based estimate with confidence bands indicated by thin solid lines. The dashed lines are the nonparametric fits, and the grey circles indicate the recorded observations. To see better the curvature, we have also plotted a $45^{\circ}$ line, and a horizontal line at $\alpha=0$. The functions are estimated from different samples taken from the sources discussed in Section 2. For Basque we have data from between 53 to 175 municipalities per year

\footnotetext{
${ }^{35}$ Specifically, we used the command locfit of the R-package 'locfit' with degree 1 and nearest neighbour fraction set to 0.25 for Basque and Welsh, but the 0.7 for Irish due to the extremely asymmetric distribution. These settings were also used for the test statistics.
} 
(from Soziolinguistika Klusterra), for Irish from about 180 so-called 'local electoral areas' obtained from different censi, and for Welsh from 22 local authorities, cf. Tables 2 to 4 in the Appendix.

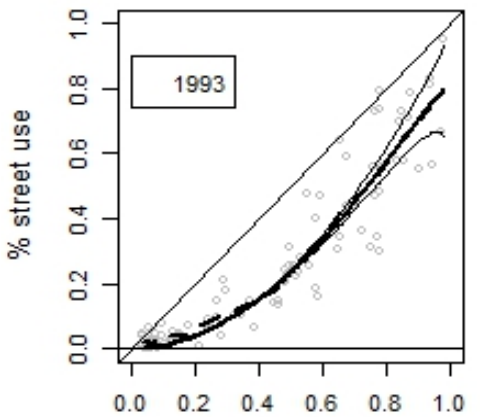

$\%$ of bilinguals

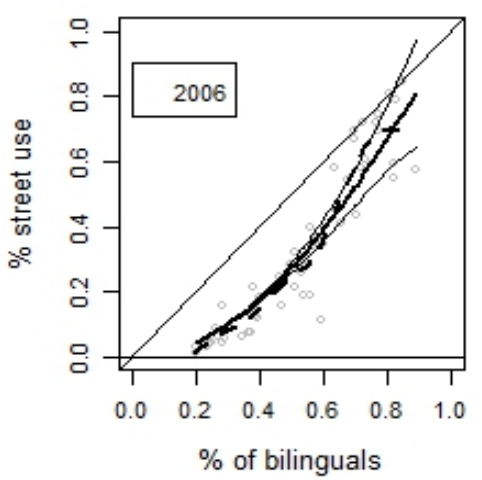

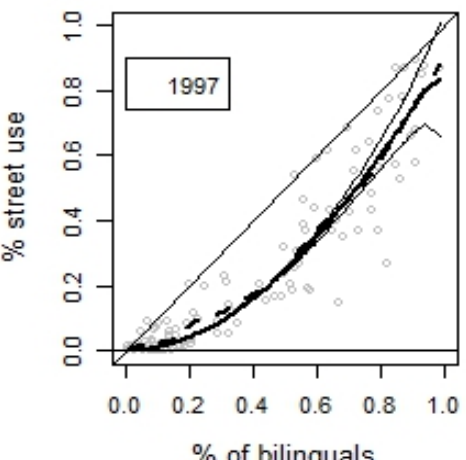
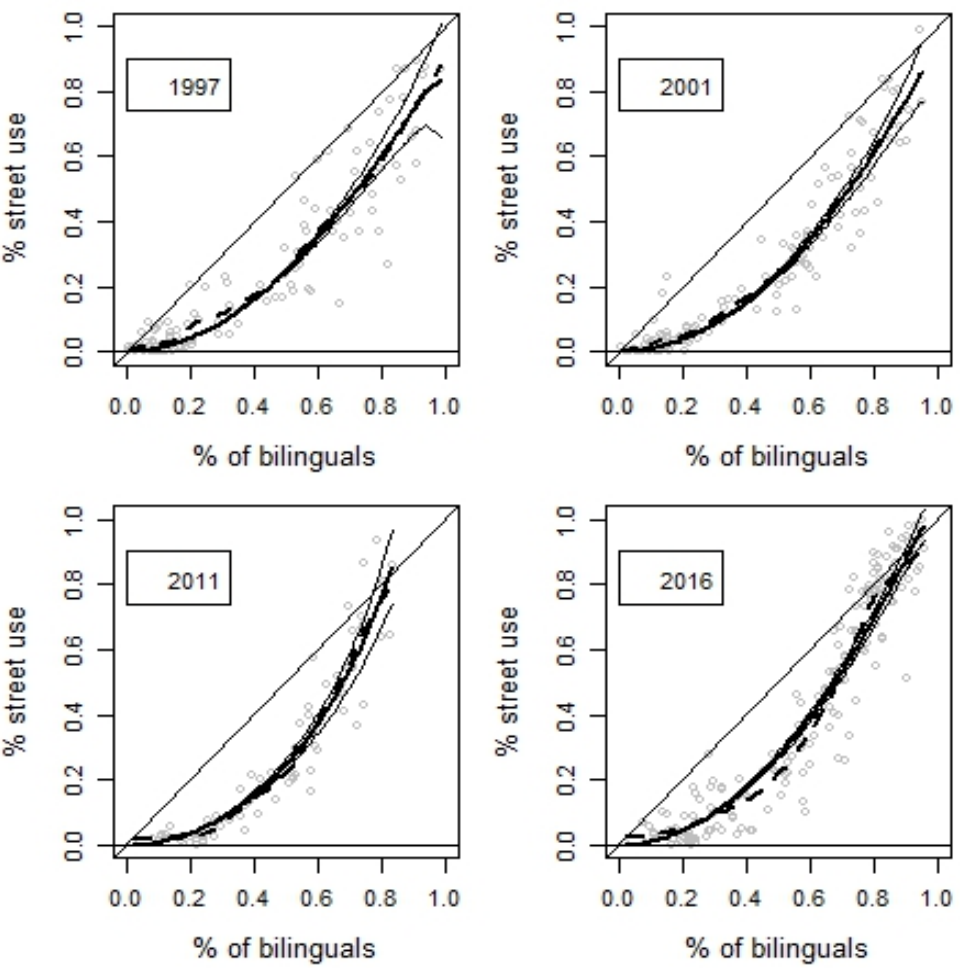

Figure 2: Solid lines: $P K E$ for Basque, thick line is the estimate, thin lines give the $99 \%$ confidence bands. The dashed lines are nonparametric kernel regression fits.
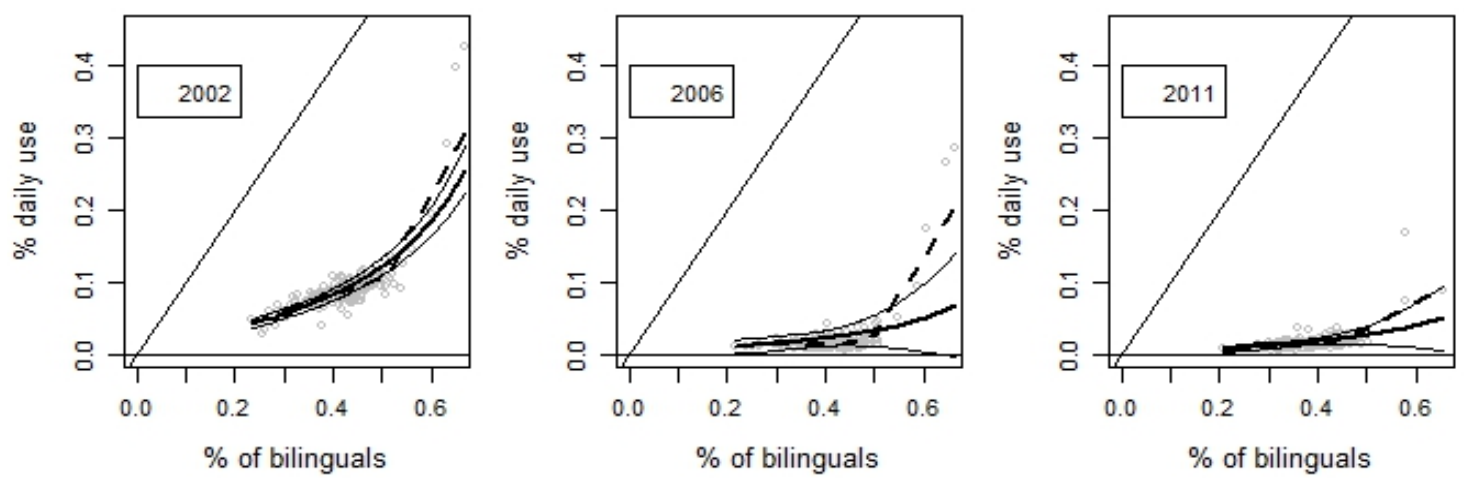

Figure 3: Solid lines: $P D U$ for Irish, thick line is the estimate, thin lines give the 99\% confidence bands. The dashed lines are nonparametric kernel regression fits.

For both, Basque and Irish we see that, over time, the functions are quite stable, 

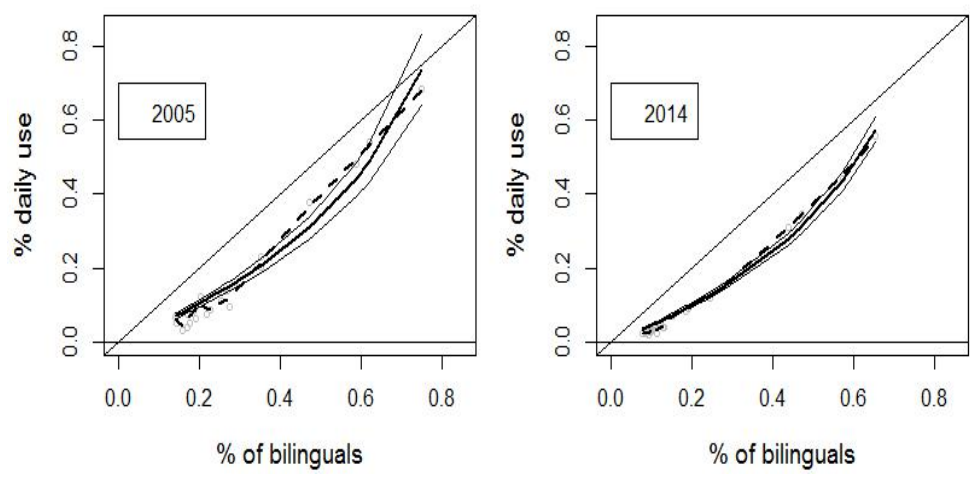

Figure 4: Solid lines: $P D U$ for Welsh, thick line is the estimate, tin lines give the 99\% confidence bands. The dashed lines are nonparametric kernel regression fits.

even over a period of almost 25 years ${ }^{36}$ The $P D U$ for Welsh is almost parallel to the $45^{\circ}$ line. When $\alpha$ is above 0.6, i.e. bilinguals are a clear majority, then the function immediately shifts to the $45^{\circ}$ line. All model-based estimates come very close to the nonparametric (i.e. model-free) data fits, except maybe for extreme values and outliers. In particular, most of the time the confidence bands include the nonparametric fit. All this clearly confirms our theory discussed in the previous sections, and thus, supports our extended LUG model.

Further, for Irish we see a clear difference compared to Welsh and Basque. The latter two have a more intensive use than Irish, which seems to be shifted away. For Basque, it even seems that the curvature is getting closer to the $45^{\circ}$ line; this is studied further below. But before doing so, we complete the empirical study of our hypothesis, Propositions 1 and 2 , by another formal test. We say 'another' since the provision of confidence bands is equivalent to a particular statistical test.

More specifically, we apply the nonparametric specification test of Härdle and Mammen (1993) which takes as test statistic the Euclidean distance between the smoothed version of the model-based parametric fit and the nonparametric fit. The 'smoothed version' means that the parametric fit gets convoluted with the same kernel and bandwidth we used for the nonparametric fit to avoid rejecting our hypothesis simply because of a smoothing bias inherited by the nonparametric fit. Then the bootstrap p-values are: for Basque 0.728 for 1993, 0.408 for 1997, 0.559 for 2001, 0.054 for 2006, 0.479 for 2011, and 0.003 for 2016. For Irish 0.055 for 2002, 0.032 for 2006, and 0.095 for 2011; and for Welsh we get a p-value of 0.075 for 2005 and 0.080 for 2014. This, together with the graphs, indicate that the model adapts reasonably

\footnotetext{
${ }^{36}$ For Ireland we mainly refer to 2006 and 2011 because of the uncertainty concerning the measurement of $D U$ before 2006. People may use every day Irish only at school, but elsewhere choose strategy $H$. Only since 2006 there is a clear definition of $D U$ outside the educational system.
} 
well to the observed data. The reason for the low p-values in some years, that can also be detected in the pictures, is due to the $\alpha$ values for which the nonparametric line is far outside the confidence bands.

To calculate the p-values, uniform confidence bands, standard errors and confidence intervals, we generated 1000 bootstrap samples $\left\{Y_{i}^{*}, \alpha_{i}\right\}_{i=1}^{n}$ where $Y_{i}^{*}:=\widehat{Y}_{i}+\left(Y_{i}-\widehat{Y}_{i}\right)$. $\varepsilon_{i}$ with $Y_{i}$ being $K E_{i}$ (or $D U_{i}$ ), $\widehat{Y}_{i}$ our estimated prediction model, and $\varepsilon_{i}$ randomly drawn from a standard norma ${ }^{37}$. Then, for example the uniform confidence bands for $P K E$ were constructed in the following way. Define

$$
T:=\sup _{\alpha \in(0,1)}|P K E(\alpha)-\widehat{P K E}(\alpha)| / \sigma_{y}(\alpha)
$$

with $\sigma_{y}^{2}(a)=\operatorname{Var}[\widehat{P K E}(a)]$. It can be shown that its bootstrap analogue

$$
T^{*}:=\sup _{\alpha \in(0,1)}\left|P K E^{*}(\alpha)-\widehat{P K E}^{*}(\alpha)\right| / \sigma_{y}^{*}(\alpha)
$$

is converging in distribution to $T$. Consequently, from our bootstrap samples we can obtain any quantile $q_{T}$ of $T$. The formula $\widehat{P K E}(\alpha) \pm q_{T}^{*} \sigma_{y}^{*}(\alpha)$ provides us with uniform confidence bands at any wanted quantile. The confidence bands (as the confidence intervals) can be asymmetric because they are calculated by this bootstrap method, and therefore reflect the asymmetry of the distributions of our estimators.

These uniform bands are very useful as the nonparametric test simply tells us whether the theory model has a low p-value or not; it does not tell us where a potential problem is. In our case, the bands provide us with the information that there is not a general, systematic deviation of our theory model from the nonparametric fit. In fact, apart from outlier problems on the right hand side of the Irish data, the low p-values for Basque in 2016 and Irish in 2006 are due to an 'elbow' of the real data (respectively the nonparmaetric fit) at around $\alpha=0.5$, i.e. when bilinguals become the majority.

We said above that Irish is almost shifted, whereas the use of Basque is quite stable. Having made these observations, it would be interesting to contrast them with the development of $\alpha$ and $K E$ (or $D U$ ) over time. The box-plots (left panels) in Figures 5 7 7 illustrate the development of the distributions over the years. Recall that we are looking at all combinations $\left(\alpha_{t i}, K E_{t i}\right)$ without weighting them by the population size of municipality $i$. This explains why it seems that the percentage(s) of bilingual

\footnotetext{
${ }^{37}$ We also checked with centred and normalised chi-square to guarantee non-negative responses (Pendakur, Scholz, Sperlich, 2010), and a two-point distribution (Härdle, Mammen, 1993) to account better for potential asymmetries. We present the version with standard normal $\varepsilon_{i}$ as these seem to calibrate best nonparametric test for moderate sample sizes, see Sperlich (2014).
} 

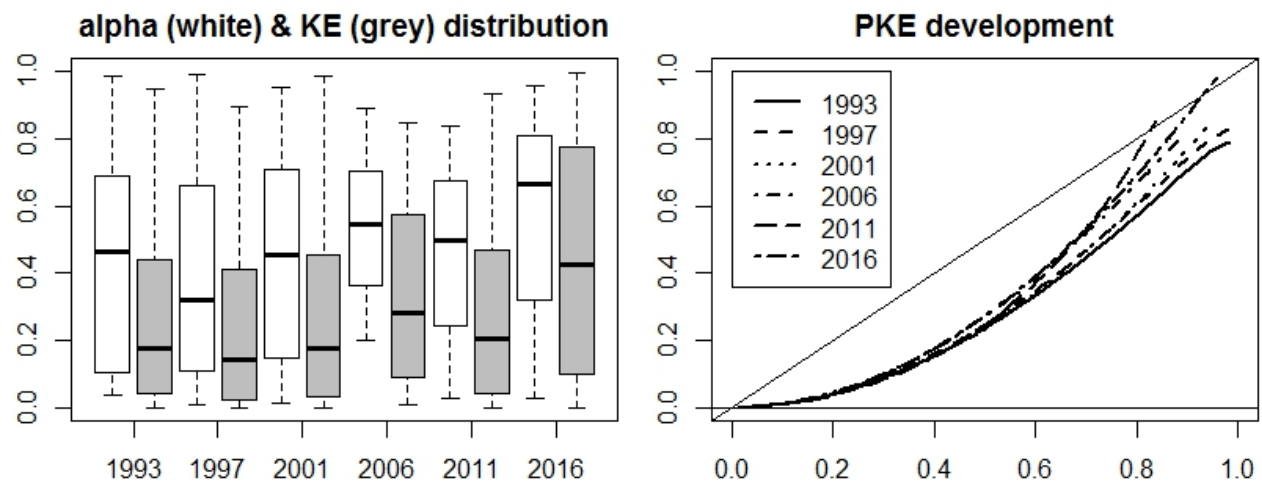

Figure 5: The development of $\alpha$ and street use of Basque over time.
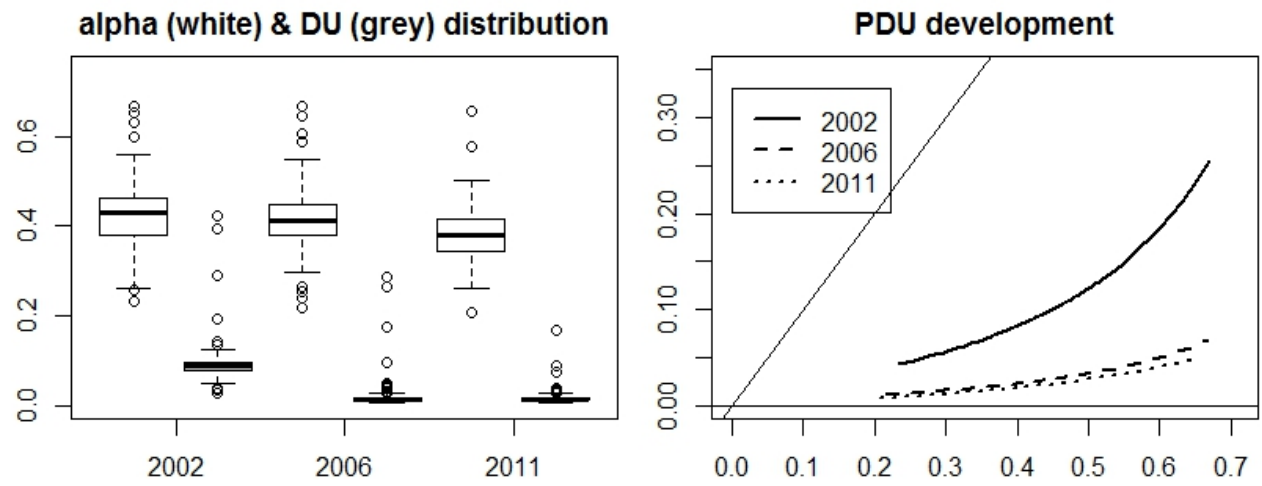

Figure 6: The development of $\alpha$ and daily use of Irish over time.

speakers went down, though the real total percentage has steadily increased, see Table 1. We see that all years exhibit a huge dispersion for $\alpha$ and $K E$ (less so $D U$ ), with no stabilization of the distributions of these indicators. We observe a shrinking number of municipalities with small $\alpha$ and/or small values of $K E$. This might
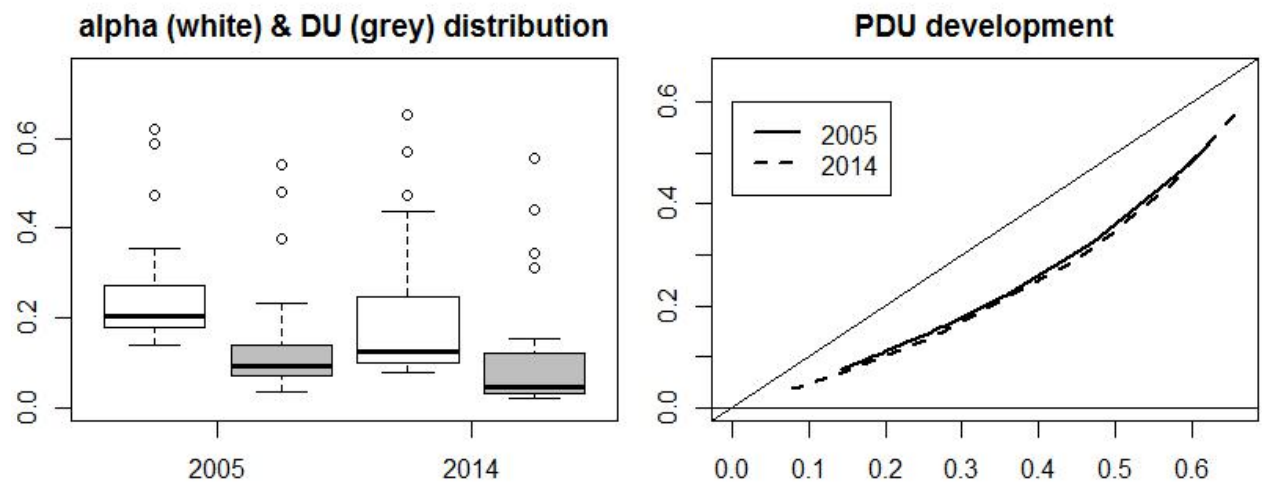

Figure 7: The development of $\alpha$ and daily use of Welsh over time. 
explain why people feel that $\alpha$ has to increase much more to become a normalized language ( $\beta_{3}$ is converging to zero from above!). What we see in the right panels is the development of $P K E$ and $P D U$ over time. The tendency is clear: for Irish it went down dramatically from an almost low level, whereas for Basque it is steadily increasing. As for Welsh we only have two points in time which certainly give different results; thus, we prefer not to interpret the observed change.

We close this empirical analysis by noting that we also run estimations and test for Model 1 , and for $x^{*}$ with $m$ and $c$ constant, as well as with other flexible net benefit functions allowing to violate one of our assumptions. They neither fit better but get smaller p-values. All these results are provided on request. We can conclude that we could not find any empirical evidence against our theory based model.

\section{Conclusions}

This paper has taken an evolutionary game-theoretic approach to analyse the observed erosion in the minority language use in modern multilingual societies, like the Basque Country, Ireland and Wales (the benchmark societies). Certainly, manifold factors could influence a minority culture, such as the developments of information technologies, globalization and international market integration. Olivier et al.(2008), Bisin and Verdier (2010) and (2014) study the impact of international integration on cultural identities with the cultural dynamics model of Bisin and Verdier (2001) interacting with a model international trade equilibrium. We do not deny the influence of globalization on cultural identities. However, on a more specific level, such as the analysis of minority language use, we rather take an internal view, focusing, as suggested by the Council of Europe, on the speaker of the minority language $B$, i.e., the bilingual individual, and the factors that might shape his language choices.

Our model shows that the bilingual population dynamics converge into an (interior) evolutionary stable Nash equilibrium (i.e., a linguistic convention), $x^{*}$, that denotes the equilibrium fraction of bilinguals who choose pure strategy Reveal $(R)$. In this equilibrium, when pairs of bilinguals playing $\operatorname{Hide}(H)$ are matched, with probability $\left(1-x^{*}\right)\left(1-x^{*}\right)$, they will shift to speak in the majority language $A$. Since the strategies $R$ and $H$ have equal expected payoffs, the linguistic convention is compatible with any value of $x^{*} \in(0,1)$. Then it is possible that $H$ could create a positive feedback loop; that is, more bilinguals would choose it, increasing $1-x^{*}$. As a result, a convention with a relatively low fraction of $R$ choosers may, by imitation learning, expand through the bilingual population, reaching domains where asymmetric information does not exist, such as family, and assortative matchings. 
Hence, we have a theoretical explanation for the erosion observed in the minority language use. To test the theory, we build three empirical equilibrium models, each giving rise to an increasing and convex relation between the proportion of bilinguals, $\alpha$, in each context and the predicted use of $B$ in equilibrium ${ }^{38}$. We show that these equilibrium functions explain very well the observed data for all languages and years. They are quite stable over time, for each language, and the performed nonparametric tests do not reject our model. The empirical result is that the extended LUG is a solid model to analyse the erosion in the use of language $B$.

One wonders why bilinguals could behave in that (paradoxical) way? The strategic analysis of language use of this paper throws light to understand this behaviour. It is well known that human language is guided by economizing attitudes 39 , and the principles of least effort, see Zipf (1949) ${ }^{40}$ Our framework points in the same direction. More specifically, contrary to the strategy $R$, the chooser of $H$ minimizes potential frictions with monolinguals, and takes a passive role in determining the language of interaction. Further, $H$ avoids the frustration cost $c$. Thus, it should not be a surprise that bilinguals might converge into a linguistic convention in which the least effort demanding strategy $H$ is chosen by a relevant fraction of the bilingual population which, in turn, would result in a decrease in the use of $B$.

Since the goal is to increase the use of $B$, our model suggests that the main policy target should be to increase $x^{*}(\alpha)$. Therefore, all the elements entering into equation (3) should be taken into account: $\alpha(m(\alpha)-n), c(\alpha)$ and $\alpha$. Needless to say, the imperfect information should be minimized. In fact, its influence on minority language use has been neglected in language economics (see Ginsburgh and Weber, Ed., 2016), sociolinguistics (Bayley, Cameron and Lucas, Ed., 2013), and in the theories developed after the Abrams and Strogatz (2003)'s model (see Patriarca et al., 2012). There are simple ways to transmit information, like the Cymraeg badges proposed by the Welsh Language Commission so that Welsh speakers would recognize each other. But this kind of signalling could be controversial. For example, it would not be politically accepted in the Basque Country. Indeed, the type of signalling (verbal or non verbal) can only be adopted if it has a wide social consensus. Verbal signalling could be more complicated. Linguistic planners could consider the

\footnotetext{
${ }^{38}$ It could be argued that intuition might suggest that the predictive functions should be increasing and convex. However, these two properties alone cannot explain the variation observed in the data. There is, still, plenty of space for model mis-specification.

${ }^{39}$ Characterized by the optimization of the difference between communication benefits and the costs attached to the speech production (in each of the two active language system, in the case of a bilingual): memory, word length, utterance length, frequency and other factors; see Frank and Goodman (2012).

${ }^{40}$ These features are also confirmed by Selten and Warglien (2007) in their experiment on the emerging of an artificial language.
} 
monolinguals as potential allies. To this end, careful pondered introductory phrases could be designed, to be used by bilinguals to convey the desire to speak $B$; also, well thought answers should be chosen for the monolinguals to convey that they do not feel under pressure nor are embarrassed to confess they do not speak the official language $B$. Since the interactions with monolinguals are frequent, their cooperative attitude would make bilinguals to gradually ignore politeness-based choices, and reveal more openly their type. Friendliness could also alleviate frustration costs.

It might require also language policy measures to increase the bilinguals' perceived net benefit of using $B$. Policies could also highlight the advantages (both cultural and psychological) of being an active bilingual, taking part in keeping alive language $B$ and its related culture, and sustain cultural diversity.

A dramatic increase in $\alpha$ is not necessarily the definitive solution to increase the use of $B$, as it has been proved by comparing Ireland, Wales, and the Basque Country: while the percentage of bilinguals in Ireland doubles the one in the Basque Country, the former is close to extinction while the latter exhibits a fairly stable street use. One may think that this is because English (the majoritarian language $A$ ) is a stronger competitor for Irish $(B)$ than Castellano and French is for Basque (though Spanish is after English, Chinese and Hindi the fourth most spoken language in the world). For this reason we added Welsh which has an $\alpha$ similar to the one of Basque.

Like any model, ours has limitations. There may be other factors outside the model that hinder the use of $B$. For example, with the empirical Model 2 we already capture partially the bilinguals' politeness behaviour, and find that it explains better the data of street use of Basque (compared with Model 1). This suggests that politeness is a relevant feature to understand the use of $B$. One could extend the LUG further by introducing explicitly politeness. This would imply a different theoretical scenario, with different Nash equilibria and linguistic conventions; see Uriarte (2017) for a preliminary study.

\section{References}

Abrams D.M. and Strogatz S.H. (2003). "Modeling the dynamics of language death," Nature 424, 900.

Altuna, O. and Basurto, A. (2013). A Guide to Language Use Observation. Survey Methods. Soziolinguistika Klusterra.

Amorrortu, E.. Ortega, A. Idiazabal, I. and Barreña, A. (2009). Actitudes y 
Prejuicios de los Castellanohablantes Hacia el Euskera. Eusko JaurlaritzaBasque Government: Vitoria-Gasteiz.

Robert Bayley, Richard Cameron, and Ceil Lucas (eds.) (2013). The Oxford Handbook of Sociolinguistics. Oxford. Oxford University Press.

Anderlini, L. and Felli, L. (2004). "Book Reviews: Economics and language," Economica 71, 169-179.

Baztarrika, P.(2014). "Euskararen hazkundearen paradoxak," http://www.erabili.eus/zer_berri/muinetik/.

Begum, G. and Richter, M. (2015). "An experiment on aspiration-based choice," Journal of Economic Behavior \& Organization 119, 512-526.

Begum, G., Richter, M. and Tsur, M. (2016). "Aspiration-based choice theory," Working Paper.

Binmore, K. Gale, J. and Samuelson, L.(1995). "Learning to be imperfect: The ultimatum game," Games and Economic Behavior 8, 56-90

Bisin, A and Verdier, T. (2001). "The economics of cultural transmission and the dynamics of preferences," Journal of Economic Theory 97, 298-319.

Bisin, A., Verdier, T. (2010). "The economics of cultural transmission and socialization," in Benhabib, J., Bisin, A., Jackson, M. (eds.), The Handbook of Social Economics. Elsevier: New York.

Bisin, A and Verdier, T. (2014). "Trade and Cultural Diversity," in Ginsburgh, V. and Throsby, D. (eds.) Handbook of the Economics of Art and Culture, Vol.2. Amsterdam: Elsevier.

Blume, A. and Board, O. (2013). "Language barriers," Econometrica 81(2), 781812.

Brown, P. and Levinson, S.C. (1987). Politeness: Some Universals in Language Usage. Cambridge: Cambridge University Press.

Cabrales, A. (2000). "Stochastic replicator dynamics," International Economic Review 41, 451-481

Cabrales, A. and Uriarte, J.R. (2013). "Doubts and equilibria," Journal of Evolutionary Economics 23(4), 783-810.

Cavalli-Sforza, L. and Feldman, M. (1981). Cultural Transmission and Evolution: A Quantitative Approach. Princeton, NJ: Princeton University Press. 
Council of Europe. http://www.coe.int/t/dg4/education/minlang.

Crystal, D. (2000). Language Death, Cambridge: Cambridge University Press.

Desmet, K., Ortuño-Ortín, I. and Weber, S. (2009). "Linguistic diversity and redistribution," Journal of the European Economic Association 7(6), 1291318.

Fishman, J.A. (1991). Reversing Language Shift. Theoretical and Empirical Foundations of Assistance to Threatened Languages. Clevedon, UK: Multilingual Matters.

Fishman, J.A. (2001). "Why is it so hard to save a threatened language?" in J.A. Fishman (ed.) Can Threatened Languages be Saved? Clevedon, UK: Multilingual Matters.

Frank, M.C. and Goodman, N.D. (2012). "Predicting pragmatic reasoning in language games," Science 336(6084), 998.

Ginsburgh, V. and Weber, S. (2011). How Many Languages Do We Need? The Economics of Linguistic Diversity. Princeton, NJ: Princeton University Press.

Ginsburgh, V. and Weber, S., Ed. (2016). The Palgrave Handbook of Economics and Language. Houndmills: Palgrave MacMillan.

Grin, F., Sfreddo, C. and Vaillancourt, F. (2010). The Economics of the Multilingual Workplace. New York, NY: Routledge.

Härdle, W. and Mammen, E. (1993). "Comparing Nonparametric Versus Parametric Regression Fits," Annals of Statistics 21(4): 1926-1947.

International Journal of the Sociology of Language (2015). "Special Issue: New Speakers of Minority Languages: The Challenging Opportunity," Volume 231.

Iriberri, N. and Uriarte, J.R. (2012). "Minority language and the stability of bilingual equilibria," Rationality and Society 2(4), 442-462.

Jones, H.M. (2012). A statistical Overview of the Welsh language. The Welsh Language Board. Cardiff.

Kahneman, D. and Tversky, A. (1979). "Prospect Theory: An analysis of decision under risk," Econometrica 47(2), 263-289.

Kahneman, D., Wakker, P.P. and Sarin, R. (1997). "Back to Bentham? Explorations of experienced utility," The Quarterly Journal of Economics 112(2): 375-405. 
Landry, R. and Bourhis, R.Y. (1997). "Linguistic landscape and ethnolinguistic vitality an empirical study," Journal of Language and Social Psychology 16 (1): $23-49$.

Manski, Ch. (1997). "Identification of anonymous endogenous interactions," in B. Arthur, S. Durlauf, and D. Lane (eds) The economy as an Evolving Complex System II, Reading, Mass.: Addison-Wesley, 1997, pp. 369-384.

Maynard Smith, J. (1982). Evolution and the theory of games. Cambridge: Cambridge University Press.

Mercator (2008). The Basque language in Education in Spain. 2nd Edition. www.mercator-research.eu

Mercator (2014). The Welsh language in Education in the UK. 2nd Edition. www.mercator-research.eu

Mercator-Education (2016). The Irish language in education in the Republic of Ireland. 2nd Edition. www.mercator-research.eu

Minett, J. and Wang, W.-Y. (2008). "Modelling endangered languages: The effects of bilingualism and social structure," Lingua 118(1), 19-45.

Nelde, P.H. (1995). "Language contact and conflict: the Belgian experience and the European Union," in S. Wright and H. Kelly (eds.) Languages in Contact and Conflict: Experiences in the Netherlands and Belgium. Clevedon, UK: Multilingual Matters.

Olivier, J., Mathias T., and Verdier, T. (2008). "Globalization and the dynamics of cultural identity," Journal of International Economics 76, 356-370

Ortega, A., Urla, J. Amorrortu, E. Goirigolzarri, J. and Uranga, B. (2015). "Linguistic identity among new speakers of Basque," International Journal of the Sociology of Language 231, 85-105.

O'Rourke, B. and Ramallo, F. (2011). "The native-non-native dichotomy in minority language contexts. Comparisons between Irish and Galician," Language Problems and Language Planning 35(2): 139-159.,

Patriarca, M. and X. Castelló, Uriarte, J.R., Eguiluz, V.M. and San Miguel, S. (2012). "Modeling two Language competition dynamics," Advances in Complex Systems, 15,3-4. 
Pendakur, K., Scholz, M. and Sperlich, S. (2010). "Semiparametric indirect utility and consumer demand," Computational Statistics and Data Analysis 54: 27632775 .

Rubinstein, A. (2000). Economics and Language, Cambridge: CUP.

Schlag, K. H. (1998). "Why imitate, and if so, how?: A boundedly rational approach to multi-armed bandits," Journal of Economic Theory, 78, 130-156.

Selleck, C. (2018). "We are not fully Welsh. Hierarchies of belonging and new speakers of Welsh," in Smith-Christmas, C., Ó Murchadha, N.P., Hornsby, M., Moriarty, M. (eds.). New Speakers of Minority Languages: Linguistic Ideologies and Practices. Palgrave Macmillan, UK.

Selten R. and Pool, J. (1991). "The Distribution of Foreign Language Skills as a Game Equilibrium," in R. Selton (ed). Game Equilibrium Models IV: Social and Political Interaction, Berlin: Springer-Verlag, 64-87.

Selten, R. and Warglien, M. (2007). "The emergence of simple languages in an experimental coordination game," Proceedings of the National Academy of Science 104(18), 7361-7366.

Solé, R., Corominas-Murtra, B. and Fortuny, J. (2010). "Diversity, competition, extinction: the ecophysics of language change," Interface 7, 1647-1664.

Sperlich, S. (2014). "On the choice of regularization parameters in specification testing: a critical discussion," Empirical Economics 47(2), 427-450.

Stauffer, D. and Schulze, C. (2005). "Microscopic and macroscopic simulation of competition between Languages," Physics of Life Reviews 2(2), 89-116.

UNESCO (2002). "UNESCO Universal Declaration On Cultural Diversity"

Uriarte, J.R. (2017). "The Economics of Bilingual identity: Politeness equilibrium," Mimeo, University of the Basque Country.

Weibull, J.W. (1995). Evolutionary Game Theory. Cambridge, Mass.: the MIT Press.

Winford, D. (2003). An Introduction to Contact Languages. Oxford: Blackwell.

Young, H.P. (1995). "The economics of convention." Journal of Economic Perspectives 10, 105-122.

Zipf, G. K. (1949). Human Behavior and the Principle of Least Effort. Cambridge, Mass: Addison-Wesley Press. 


\section{Appendix}

\subsection{Language Use Data}

Note that the proportion of bilinguals in the three languages, denoted $\alpha$, is obtained dividing the Number of Bilinguals by the Total Population. For Table 1 this is the population in the country, and in the Figures in Section 4 it refers to the small regions (communities, counties, etc). The definition of who is bilingual is set by the statistical authority in each country. They coincide in that it is the oral competence what determines whether an individual is qualified as bilingual or not.

- Basque Country: The data about knowledge of Basque can be found in the Sociolinguistic Surveys (Inkesta Soziolinguistikoa). These surveys are carried out by the local Government and agencies of each of the three territories where Basque is spoken: the Basque Autonomous Community, the Navarre Community and Pays Basque. The population is divided in three groups according to the oral competence relative to Basque: Bilinguals (those who speak well or fairly well the language), Passive Bilinguals (those who do not speak well, but understand the language) and Monolinguals. The VI Sociolinguistic Survey 2016 gathered information from a sample of randomly chosen 8200 people, aged 16 and over, who answered questionnaire over the phone. See the Basque Government's gathered data about Basque in: www . euskara. euskadi . eus/r59-738/eu/contenidos/informacion/argitalpenak /eu_6092/ikuspegi_sozio_linguis.html

The Street Surveys are carried out, every five years, by the NGO Soziolinguistika Klusterra. The street surveyors collect random observations, without any interference with the subjects observed, just by listening and recording the language of conversations taking place in public spaces of the above mentioned three Administrative authorities ${ }^{41}$ Using random samples of anonymously registered conversations in the streets at a given time and place, the Street Use Measure (KE) of minority language $B$ is the number of individuals observed in conversations speaking language $B$ out of the total number of individuals observed in conversations in that place. As a methodological rule, the observers only record conversations in a single language, cf. A.1. The street use data can be found on www.soziolinguistika.org.

- Ireland: All data were obtained from the web-page of the Irish statistical institute, http://www.cso.ie/en/census/index.html. However, they clean up and change their

\footnotetext{
${ }^{41}$ For the methodological details on how the data is collected, see Altuna and Basurto (2013). Note that the $V$. Street Survey in 2006 took place in 62 municipalities with 400 street surveyors recording 185,316 conversations. In the VII. Street Survey in 2016, 187,635 conversations in 144 municipalities were recorded.
} 
web-pages regularly, such that the data we downloaded for 1996, 2001/2 and 2005/6 cannot be found that easily anymore. We certainly provide these data on request. The 2011 data are still available but differently organized. Again we can provide them on request. For the census 2016 of Ireland, so far only results and statistics are available, but we did not find the disaggregated data that we needed for our calculations. In all censi bilinguals are defined as "Irish speakers aged 3 years and over". The daily use, $D U$, is explicitly observed, after 1996 separated into groups that daily use Irish "inside the educational system only" and those who also or exclusively use it outside the educational system. Certainly we consider the latter group. As for 1996 this distinction is not at all clear we skipped this wave in the newer version of our paper.

- Wales: The most reliable source of data about Welsh speakers are the Censi of Wales. It is not explicitly used the word bilingual as they consider "the number of people aged 3 and over able to speak Welsh". Under the heading of "able to speak Welsh" is included every person aged 3 and over who "Speaks, reads and writes Welsh" or "Speaks, reads, but does not write" or "Speaks but does not read or write". Data about the frequency of use of Welsh are in the WLUS (Welsh Language Use Surveys). The daily use, $D U$, is obtained dividing the number of "daily users" by the total population. Disaggregated data for daily use of Welsh by local authorities is obtained from Jones (2012). Used sources are:

The Welsh Language Use Surveys of 2004-06. The Welsh Language Board. 2008. Cardiff.

Welsh Language Use in Wales 2013-15. Welsh Government and Welsh Language Commissioner. 2015. Cardiff.

Jones, H.M. (2012). A Statistical Overview of the Welsh Language, The Welsh Language Board. Cardiff.

2001 Census: Report on the Welsh Language. Office for National Statistics, London: TSO. 2004.

2011 Census. First results on Welsh, Statistical Bulletin 118/2012. Statistics for Wales.

Additional data: We send two Excel files with data about Irish and Basque. In the latter case, the headings were written in Basque with English acronyms by the surveyors who collected the data. The headings in the columns are: Year (1991, 1996, 2001, 2006, 20011 and 2016 when the Sociolinguistic Survey was made), Municipality, Bilinguals (Euskaldunak), Passive Bilinguals (Ia Euskaldunak), Monolinguals (Erdaldunak); then come the percentages of Bilinguals, Passive Bilinguals, 
and Monolinguals. Year (1993, 1997 2001, 2006, 2011 when the Street Surveys were made), Street Use of Basque (Euskera Erabilera). In the 2016 Excel file the headings are: Municipality (Udalerria), Year of the Survey (Neurketa), Bilingual (Gaitasuna), Sample Size (Lagina), Street Use of basque (Euskera Erabilera).

\subsection{Matrix of Expected Pay-offs and Replicator Equation}

The matrix of expected pay-offs attached to the LUG is the following:

\begin{tabular}{c|c|c|}
\multicolumn{2}{c}{$\mathbf{R}$} & $\mathbf{H}$ \\
\cline { 2 - 4 } $\mathbf{R}$ & $\alpha(m-n)-c(1-\alpha), \alpha(m-n)-c(1-\alpha)$ & $\alpha(m-n)-c(1-\alpha), \alpha(m-n)$ \\
\cline { 2 - 3 } $\mathbf{H}$ & $\alpha(m-n), \quad \alpha(m-n)-c(1-\alpha)$ & $0, \quad 0$
\end{tabular}

This is a symmetric matrix. Let $x$ be the proportion of bilinguals playing strategy $R$. To simplify notation, let $\mathbf{h}=\alpha(m-n)-c(1-\alpha)$, and $\mathbf{j}=\alpha(m-n)$. Then $\mathbf{A}$ denotes the matrix of pay-offs to the bilingual player in the row position:

$$
\mathbf{A}=\left[\begin{array}{cc}
\mathbf{h} & \mathbf{h} \\
\mathbf{j} & 0
\end{array}\right]
$$

Since we are dealing with a symmetric two player game, the pay-off matrix to the bilingual player in the column position, denoted $\mathbf{B}$, will be the transpose of matrix $\mathbf{A}: \mathbf{B}=\mathbf{A}^{\mathbf{T}}$. Members of the bilingual population are divided in two types, those who choose pure strategy $R$, and those who choose $H$, with proportions $x$ and $1-x$, respectively. The success of a bilingual type is a function of the population state $\mathbf{x}=(x, 1-x)$. Since the LUG is played continuously by pairwise random matches, we may assume that the state $\mathbf{x}(t)$ evolves as a differentiable function of time $t$. The rate of increase $\dot{x} / x$ of the type $R$ depends on the expected pay-offs to strategy $R$ ( that is, $\mathbf{A x}$ ) relative to the average expected pay-offs (that is, $\mathbf{x}^{\mathbf{T}} \mathbf{A x}$ ). Thus, we obtain the one-population replicator dynamics equation associated to the LUG, as follows,

$$
\frac{\dot{x}}{x}=\mathbf{A x}-\mathbf{x}^{\mathbf{T}} \mathrm{Ax}
$$

Clearly $\frac{\dot{x}}{x}>0$ if $\mathbf{A x}>\mathbf{x}^{\mathbf{T}} \mathbf{A x}, \frac{\dot{x}}{x}<0$ if $\mathbf{A x}<x^{\mathbf{T}} \mathbf{A} \mathbf{x}$, and $\frac{\dot{x}}{x}=0$, otherwise. The bilinguals who choose $H$ will evolve in the opposite direction to that of $R$, so there is no need to indicate the differential equation of $1-\dot{x}$. Doing the operations shown in the replicator equation, we obtain the differential equation for the evolution of the share of bilinguals playing pure strategy $R$ :

$$
\dot{x}=x(1-x)[\alpha(m-n)(1-x)-c(1-\alpha)]
$$


The rest points for the equation are $x=1, x=0$ and the mixed strategy equilibrium $x^{*}=1-\frac{c(1-\alpha)}{\alpha(m-n)}$. When $0<x<x^{*}, x$ increases toward $x^{*}$, and when $1>x>x^{*}$, $x$ decreases toward $x^{*}$. Thus, the asymmetric equilibria $(R, H)$ and $(H, R)$ are unstable, and $x^{*}$ is evolutionary stable.

Remarks: The equilibria of the LUG, in the framework of pairwise strategic interactions represented as a symmetric two player game, need the following assumptions:

1. The player role or position in the game does not condition the choice of action. That is, both the row player (or player I) and the column player (or player II) will choose freely either $R$ or $H$. On this issue, see Weibull (1995) and the quoted references therein.

2. Who is the speaker (or who initiates the conversation), and who is the listener (or hearer) is not conditioned by the player position nor by the choice of strategy. In particular, the row (column) player is not necessarily the speaker (listener). An $R$ chooser (either row or column player) may lead the language $B$ coordination process either as speaker or as listener. An $H$ chooser is passive in that coordination.

\subsection{The Parameter Estimates}

Table 2: Parameter estimates (with standard deviations in parenthesis) and 95\% bootstrap confidence intervals (C.I.) for the Basque municipals; obs. indicates number of observations.

\begin{tabular}{l|llllll} 
year & 1993 & 1997 & 2001 & 2006 & 2011 & 2016 \\
\hline \hline$\beta_{1}$ & $.862(.045)$ & $.890(.027)$ & $.946(.024)$ & $1.07(.026)$ & $.849(.036)$ & $1.10(.024)$ \\
C.I. & {$[.778 ; .905]$} & {$[.857 ; .929]$} & {$[.918 ; 1.02]$} & {$[1.03 ; 1.13]$} & {$[.776 ; .934]$} & {$[1.09 ; 1.17]$} \\
$\beta_{2}$ & $.034(.018)$ & $.030(.015)$ & $.003(.014)$ & $.039(.036)$ & $-.191(.031)$ & $.008(.009)$ \\
C.I. & {$[-.002 ; .070]$} & {$[.000 ; .060]$} & {$[-.019 ; .035]$} & {$[-.021 ; .116]$} & {$[-.233 ;-.116]$} & {$[.000 ; .033]$} \\
$\beta_{3}$ & $.082(.039)$ & $.089(.024)$ & $.011(.011)$ & $.032(.023)$ & $.013(.023)$ & $.001(.005)$ \\
C.I. & {$[.043 ; .155]$} & {$[.055 ; .116]$} & {$[.000 ; .036]$} & {$[.001 ; .096]$} & {$[.001 ; .088]$} & {$[.000 ; .015]$} \\
\hline \hline obs. & 95 & 116 & 127 & 53 & 74 & 175
\end{tabular}

\subsection{Nonparametric Estimation procedure}

For the ease of notation we always use $K E$ as observed response variable; for $D U$, the methodology works exactly the same way. Given a sample $\left\{\alpha_{i}, K E_{i}\right\}_{i=1}^{n}$ one wants 
Table 3: Parameter estimates (with standard deviations in parenthesis) and $95 \%$ bootstrap confidence intervals (C.I.) for the Irish local election areas; obs. indicates number of observations.

\begin{tabular}{l|lll} 
year & 2002 & 2006 & 2011 \\
\hline \hline$\beta_{1}$ & $.043(.012)$ & $.007(.375)$ & $.020(.144)$ \\
C.I. & {$[.042 ; .082]$} & {$[.007 ; 1.41]$} & {$[.016 ; .513]$} \\
$\beta_{2}$ & $-1.31(.080)$ & $-1.42(1.28)$ & $-1.02(.802)$ \\
C.I. & {$[-1.32 ;-1.05]$} & {$[-1.509 ; 3.04]$} & {$[-1.15 ; 2.27]$} \\
$\beta_{3}$ & $.237(.043)$ & $.317(.103)$ & $.100(.093)$ \\
C.I. & {$[.101 ; .245]$} & {$[.035 ; .514]$} & {$[.009 ; .472]$} \\
\hline \hline obs. & 180 & 180 & 200
\end{tabular}

Table 4: Parameter estimates (with standard deviations in parenthesis) and $95 \%$ bootstrap confidence intervals (C.I.) for the Welsh local authorities. Estimates are based on 22 observations in 2004-06.

\begin{tabular}{c|ll|ll} 
& \multicolumn{2}{|c}{$2004-2006$} & \multicolumn{2}{c}{$2013-2015$} \\
& estimate (s.e.) & $95 \%$ C.I. & estimate (s.e.) & $95 \%$ C.I. \\
\hline \hline$\beta_{1}$ & $.461(.046)$ & {$[.335 ; .527]$} & $.429(.019)$ & {$[.391 ; .475]$} \\
$\beta_{2}$ & $-.538(.048)$ & {$[-.629 ;-.425]$} & $-.667(.025)$ & {$[-.691 ;-.579]$} \\
$\beta_{3}$ & $.004(.034)$ & {$[.000 ; .100]$} & $.004(.007)$ & {$[.0003 ; .027]$} \\
\hline \hline
\end{tabular}

to estimate the conditional expectation $E[K E \mid \alpha]=g(\alpha)$ under the assumption that $g(\cdot)$ is a smooth function having second order Lipschitz continuous derivatives. The errors $v=K E-g(\alpha)$ have finite variance. One may add some conditions on the distribution of $\alpha$ if one wants to calculate the statistical properties of the now described estimator: For a weight or kernel function $K(\cdot)$ for which we chose the Epanechnikov kernel $K(u)=0.75 \cdot\left(1-u^{2}\right)_{+}$(the subindex + indicates that the function is set to zero if $1-u^{2}$ is negative) and bandwidth $h_{x}$ we take

$$
\widehat{g(x)}=\underset{g, g_{1}}{\operatorname{argmin}} \sum_{j=1}^{n}\left(K E_{j}-g-g_{1} \cdot\left(\alpha_{j}-x\right)\right)^{2} K\left(\frac{\alpha_{j}-x}{h_{x}}\right)
$$

as an estimate for $g(x)$. This is the local linear kernel estimator. Letting $x$ run over the range of $\alpha$ (over all sample observations $\alpha_{i}$ ) we can draw than the function estimate of $g(\cdot)$ which is compared with our model for $P K E$. 